Florida International University FIU Digital Commons

$7-2-2014$

\title{
Identity, Purpose, and Well-Being Among Emerging Adult Hispanic Women
}

Vanessa L. Madrazo

Florida International University, vlmadrazo@gmail.com

DOI: $10.25148 /$ etd.FI14071157

Follow this and additional works at: https://digitalcommons.fiu.edu/etd

\section{Recommended Citation}

Madrazo, Vanessa L., "Identity, Purpose, and Well-Being Among Emerging Adult Hispanic Women" (2014). FIU Electronic Theses and Dissertations. 1514.

https://digitalcommons.fiu.edu/etd/1514

This work is brought to you for free and open access by the University Graduate School at FIU Digital Commons. It has been accepted for inclusion in FIU Electronic Theses and Dissertations by an authorized administrator of FIU Digital Commons. For more information, please contact dcc@fiu.edu. 


\title{
FLORIDA INTERNATIONAL UNIVERSITY \\ Miami, Florida
}

\section{IDENTITY, PURPOSE, AND WELL-BEING AMONG EMERGING ADULT HISPANIC WOMEN}

\author{
A dissertation submitted in partial fulfillment of \\ the requirements for the degree of \\ DOCTOR OF PHILOSOPHY \\ in \\ PSYCHOLOGY \\ by \\ Vanessa Lynn Madrazo \\ 2014
}


To: Interim Dean Michael R. Heithaus

College of Arts and Sciences

This dissertation, written by Vanessa Madrazo and entitled Identity, Purpose, and WellBeing Among Emerging Adult Hispanic Women having been approved in respect to style and intellectual content, is referred to you for judgment.

We have read this dissertation and recommend that it be approved.

$\begin{array}{r}\hline \text { Leslie D. Frazier } \\ \hline \text { Dionne P. Stephens } \\ \hline \text { Asia A. Eaton } \\ \hline \text { Thomas G. Reio, Jr. } \\ \hline \text { Mary J. Levitt, Major Professor }\end{array}$

Date of Defense: July 2, 2014

The dissertation of Vanessa Lynn Madrazo is approved.

Interim Dean Michael R. Heithaus College of Arts and Sciences

Dean Lakshmi N. Reddi University Graduate School

Florida International University, 2014 
C Copyright 2014 by Vanessa Lynn Madrazo

All rights reserved. 


\section{DEDICATION}

For Henry. (lek) ${ }^{5}$ 


\section{ACKNOWLEDGMENTS}

I would not be here if it weren't for the countless educators who have influenced me over the course of the years. I would like to thank each and every one of you for inspiring me through your instruction and guidance. I would also like to thank everyone at FIU who has assisted me with this project, especially Dr. Kurtines, Dr. Stephens, Dr. Frazier, Dr. Eaton, Dr. Reio and last but not least, Dr. Levitt, who truly helped this project move towards completion. Thank you all for your expertise and assistance in improving the quality of my dissertation.

Enrolling in this program, completing the requirements, and continuing until completion was much easier said than done. I am thankful for everyone who has encouraged me in this process, including the McKnight Doctoral Fellowship Program. The people at MDF have been like a second family to me since day one. Even though I thought the opportunity had passed, fate encouraged me to apply and God graced me with a Fellowship to help fund my doctoral studies. Thank you to everyone at the Florida Education Fund and I am looking forward to getting my jacket in October!

I would also like to thank the colleagues and friends that I have met while pursuing this degree of Doctor in Philosophy. I am also thankful for friendships over the years that have kept me sane and grounded. Thanks for your words of encouragement and support, that have helped me stay the course and continue to pursue my dreams.

I would not be here today if it weren't for an incredibly supportive family. Thanks to my mother Beatrice, who traded Brazil for Detroit in the 1970s in order to pursue an illustrious career in radiology. Mom, I feel closer to you by completing this $\mathrm{Ph}$. D, because it's shown me the triumphs and challenges associated with being a professional 
Latina in the United States. Agradeço todo día e amo você com todo meu coração. Thanks to my dad Armando, who has always encouraged my academic and intellectual pursuits. I'm so thankful for us keeping in touch while I was in the program, and I feel closer to you now that this journey is over. Gracias por hacerme recordar todo lo bueno

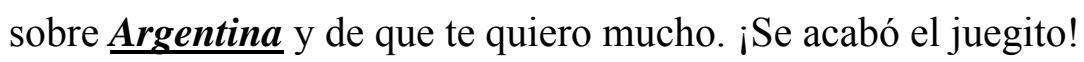

I'm also thankful for my Aunt Cecilia, who has been very close and supportive over the years. Obrigada pela sua presença, amizade, e carinho. Thanks also to my brother Marcelo, who reminds me to have fun. Thanks for being you. Thanks also to Cathy, who has been with me on this journey since moving from Michigan. Thanks for helping me stay true to myself.

Thanks also to my dog Buster, whom I recently adopted. He kept me company throughout the dissertation writing process and I'm so glad that I brought him home.

Last but certainly not least, I would like to thank my wonderful fiancée. Henry, I really don't know where I'd be without you in my life. You have the sweetest heart I have ever known and I'm so happy and excited to be sharing my life with you. Thank you for your encouragement and understanding and for bringing love into my life. I thank God for you every day. TQM. 


\section{ABSTRACT OF THE DISSERTATION \\ IDENTITY, PURPOSE, AND WELL-BEING AMONG EMERGING ADULT \\ HISPANIC WOMEN \\ by \\ Vanessa Lynn Madrazo}

Florida International University, 2014

Miami, Florida

Mary J. Levitt, Major Professor

Few studies apply the Eriksonian model of identity formation to cross-cultural samples (3), even though issues of ethnicity and culture may inform a Hispanic woman's self-concept (Phinney, 1996). Hispanic women may also be influenced by traditional gender role behaviors such as passivity or dependence that are outlined by marianismo (Stevens, 1973). A recent study of a multiethnic sample of emerging adult women and men found that purpose commitment mediated the effects of identity commitment on hope and life satisfaction (Burrow \& Hill, 2011). The current research consists of two studies that replicate and expand upon the work of Burrow and Hill (2011). Study I replicated the work of Burrow and Hill (2011) among a sample of emerging adult Hispanic women, in order to assess the extent to which the original findings would replicate in a culturally distinct sample. Study II examined the role of marianismo, ethnic identity, and acculturation on identity commitment among emerging adult Hispanic women. Both studies utilized a sample of 532 female undergraduate psychology students, age 18 to 25, who self-identified as Hispanic and submitted data via online surveys. Both studies used self-report, quantitative data, which was analyzed using structural equation 
modeling. Results from Study I indicated good model fit and replicated the findings from Burrow and Hill (2011). Specifically, the direct effect of identity commitment on hope was fully contingent upon an individual's level of purpose commitment, while the effect of identity commitment on life satisfaction was not contingent upon an individual's level of purpose commitment. Results from Study II indicated that marianismo, Spanish proficiency, familiarity with Latino culture, and familiarity with American culture demonstrated statistically significant direct effects on identity commitment among emerging adult Hispanic women. Results indicated cultural convergence regarding the association of an individual's identity with well-being through a sense of purpose. Findings also revealed the role of cultural factors in the extent to which Hispanic women commit to a personal identity. Future studies should employ mixed method research designs as a means to better ascertain implications of findings. 


\section{TABLE OF CONTENTS}

CHAPTER

PAGE

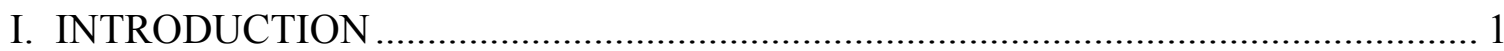

Positive Youth Development and Emerging Adulthood ................................. 1

Study I: Identity Commitment, Purpose Commitment, and Well-Being............ 4

Study II: Cultural Factors and Identity Commitment in Hispanic Women ........ 5

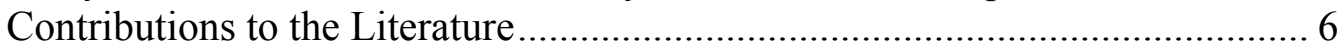

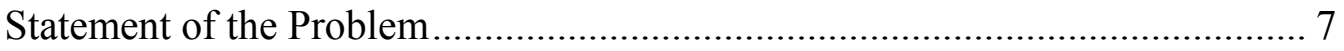

Research Questions......................................................................... 8

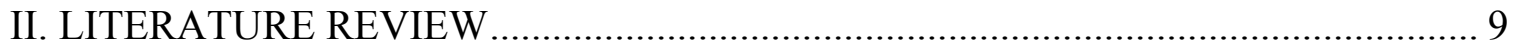

Study I: Purpose as a Mediator of the Identity-Well-Being Relationship ........ 11

Study II: Marianismo, Ethnic Identity, Acculturation ................................. 18

The Current Studies ....................................................................................... 27

Study I Hypotheses: Identity, Purpose, and Well-Being ............................... 29

Study II Hypotheses: Marianismo, Ethnic Identity, and Acculturation............ 29

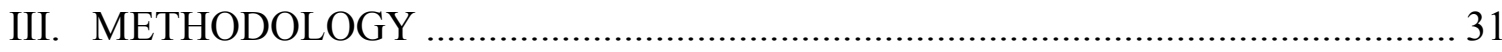

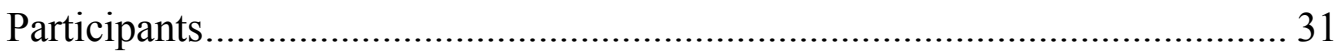

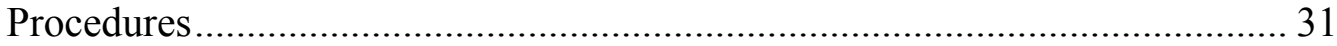

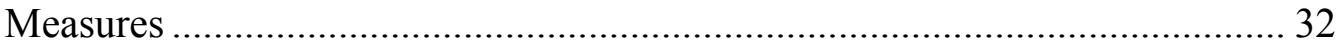

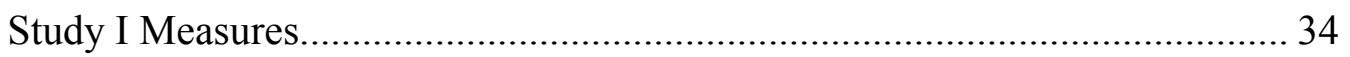

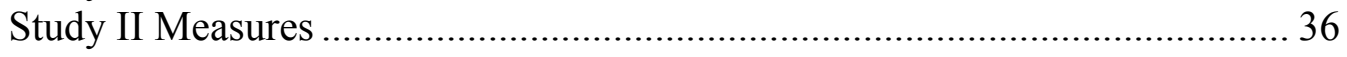

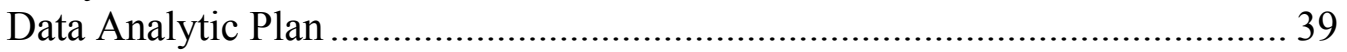

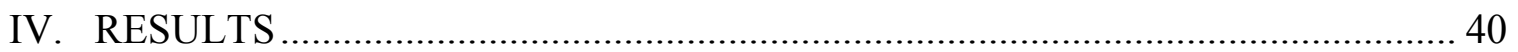

Preliminary Analyses ......................................................................... 40

Study I: Identity Commitment, Purpose Commitment, and Well-Being.......... 40

Hypotheses Testing ............................................................................... 40

Study II: Marianismo, Ethnic Identity, Acculturation and Identity ................ 44

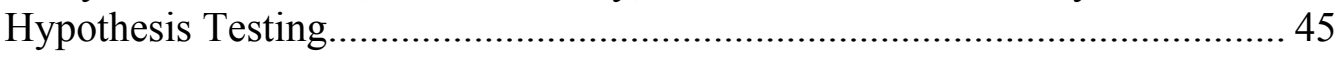

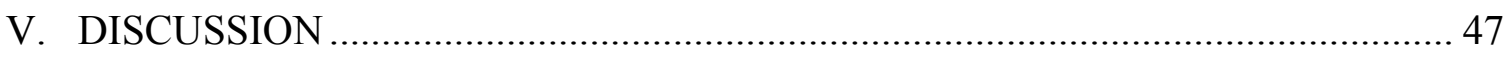

Study I: Identity Commitment, Purpose Commitment, and Well-Being.......... 47

Study II: Marianismo, Ethnic Identity, Acculturation and Identity ................ 48

Limitations of the Research ............................................................. 50

Implications and Future Directions................................................... 51

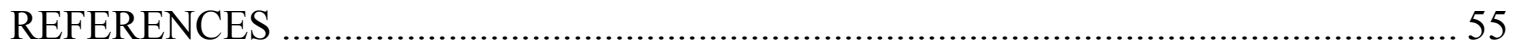




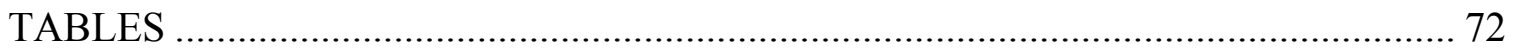

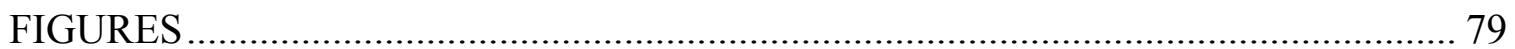

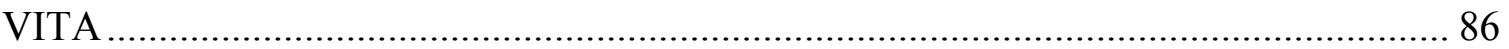




\section{LIST OF TABLES}

TABLE

PAGE

1. Descriptive Statistics of Identity, Purpose, Hope, and Life Satisfaction......................72

2. Correlations Between Identity, Purpose, Hope, and Life Satisfaction........................73

3. Direct Effects of Identity and Purpose on Hope and Life Satisfaction.........................74

4. Purpose as a Mediator of Relation Between Identity and Well-Being........................75

5. Descriptive Statistics of Marianismo, Ethnic Identity, and Acculturation Variables....76

6. Intercorrelations of Marianismo, Ethnic Identity, and Acculturation Variables...........77

7. Effects of Marianismo, Ethnic Identity, and Acculturation on Identity......................78 


\section{LIST OF FIGURES}

FIGURE

PAGE

1. Hypothesized Effects of Identity, Purpose, Hope, and Life Satisfaction......................79

2. Influence of Identity and Purpose on Hope and Life Satisfaction...............................80

3. Purpose Mediates the Relation Between Identity and Hope-Agency..........................81

4. Purpose Mediates the Relation Between Identity and Hope-Pathways........................82

5. Purpose Mediates the Relation Between Identity and Life Satisfaction.......................83

6. Hypothesized Effects of Marianismo, Ethnic Identity, and Acculturation on Identity.84

7. Direct Effects of Marianismo, Ethnic Identity, and Acculturation on Identity............85 


\section{INTRODUCTION}

\section{Positive Youth Development and Emerging Adulthood}

Adolescence as a field of research was initially developed by Granville Stanley Hall (1904) at the turn of the $20^{\text {th }}$ century. Hall was a contemporary of Sigmund Freud and Carl Jung, and characterized adolescence as a time of "storm and stress" (Lerner, Lerner, Almerigi, Theokas, Phelps, \& Gestsdottir, et al., 2005). The Positive Youth Development movement of the 19990s countered this negative impression of adolescence by positing that young people are capable of healthy development and should be viewed as resources to be developed (Hamilton, Hamilton, \& Pittman, 2004; Lerner, Dowling, Anderson, 2003). The Positive Youth Development perspective aims to foster positive development among young people by identifying mechanisms of thriving among young adults (Lerner, von Eye, Lerner, Lewin-Bizan, \& Bowers, 2010).

The Positive Youth Development movement also highlights the need to develop resilience and competency among young adults so that they may successfully navigate the challenges associated with the transition from adolescence to adulthood (Roth \& Brooks-Gunn, 2003). The term emerging adulthood (Arnett, 2000) refers to the time period between 18 and 25 years of age during which individuals set out to determine their life purpose (Hill, Burrow, Brandenberger, Lapsley, \& Quaranto, 2010). A sense of purpose is beneficial for emerging adults as they explore their identity and personality during their transition to adulthood (McKnight \& Kashdan, 2009). Purpose and identity are both associated with the pursuit and achievement of goals (Erikson, 1968; Hill \& Burrow, 2012). 
Although research on emerging adults has been extensive, there are few studies that focus on the experience of emerging adult Hispanic women. Nevertheless, the number of Hispanics in the United States is growing at a rate that is four times the national average (US Census Bureau, 2011). Miami was the location where the current research took, and is home to the $7^{\text {th }}$ largest concentration of Hispanics in the United States (Pew Hispanic Research Center, 2012). Hispanics have recently become the largest ethnic minority group on US college campuses (Cauchon \& Overberg, 2012; Pew Hispanic Center, 2012). Hispanic women outnumber Hispanic men in both college enrollment and completion (Cauchon \& Overberg, 2012; Pew Hispanic Center, 2012), but have lower rates of degree attainment when compared to African American and White women (Rodriguez, Guido-DiBrito, Torres, \& Talbot, 2000).

Research on Hispanic women in college is necessary because cultural factors may influence a person's commitment to an individualistic ego identity, which is generally promoted by Western cultures that value independence and separation (Frucht, 1995; Miville, Koonce, Darlington, \& Whitlock, 2000). Research on identity generally focuses on individual goal pursuits and personal identity, both of which may be more applicable to individualistic cultures that endorse personal autonomy, than to collectivist cultures that tend to emphasize group cohesion over individual concerns (Kagitcibasi, 2007). Thus, studies are needed that examine the experience of women from Hispanic cultures because they may be less likely to engage in identity exploration as a result of cultural precepts that discourage the development of individualistic personality characteristics (Diaz, 2004). 
Burrow and Hill (2011) studied the relations of identity and purpose well-being in emerging adulthood. Their results indicated that purpose commitment mediated the effects of identity commitment on the well-being indicators of hope and life satisfaction (Burrow \& Hill, 2011). However, the extent to which their findings would apply to a population of Hispanic women is unknown. Women from Hispanic cultures are often encouraged to adopt a self-effacing role as outlined by the concept of marianismo (Stevens, 1973), which prioritizes the good of spouses and other family members over personal concerns.

In order to address the role of culture in identity development, as well as to develop research that is relevant to current demographic trends, it is important to examine research findings on emerging adults among populations of Hispanic women. However, there is discrepancy in the literature of identity among Hispanic women in college (Owles, 2009), which has contributed to decreased understanding regarding the experiences of Hispanic women college students (Rodriguez, Guido-DiBrito, Torres, \& Talbot, 2000).

The current research included two related studies that were designed to extend the study by Burrow and Hill (2011) among a sample of emerging adult women who selfidentified as Hispanic. Study I assessed the extent to which the original Burrow and Hill findings would be replicated in this culturally divergent sample. Study II examined cultural variables that were hypothesized to contribute to ego identity commitment among emerging adult Hispanic women, namely marianismo, ethnic identity, and acculturation. These two complementary studies address the paucity of research on Hispanic youth that apply a positive developmental framework (Kuperminc, Wilkins, 
Roche, \& Alvarez-Jimenez, 2009). Furthermore, the current studies address the need as specified by Rodriguez et al. (2000) for more studies that examine the experience of Hispanic women in college (Gloria, Castellanos, \& Orozco, 2005).

\section{Study I: Identity Commitment, Purpose Commitment, and Well-Being}

Study I was designed to replicate the 2011 study by Burrow and Hill entitled "Purpose as a Form of Identity Capital for Positive Youth Adjustment," which applied the identity capital model (Côté, 1996) to inform hypotheses regarding the relations between identity commitment, purpose commitment, hope, and life satisfaction. The identity capital model proposes that an individual's identity capital consists of those parts of her or his identity that can be used to engage in tasks and capitalize on life experiences (Côté, 1996; Côté \& Schwartz, 2002). Burrow and Hill (2011) hypothesized that purpose could serve as a form of identity capital and would serve to mediate the relationship between identity and well-being.

Participants in the Burrow and Hill study provided data by completing surveys online, and were awarded course credit for their participation. A total of 398 undergraduates at a Catholic University in the Midwestern United States participated in the study ( $58 \%$ women; $M_{\text {age }}=19.0$ years, $S D=1.11 ; 65 \%$ first year students) and provided data on identity commitment, purpose commitment, hope, and life satisfaction through quantitative, self-report measures. As noted previously, results indicated that purpose commitment mediated the relationship between identity commitment and the well-being outcomes of hope and life satisfaction (Burrow \& Hill, 2011).

Specifically, purpose commitment partially mediated the relation between identity commitment and life satisfaction and fully mediated the relation between identity 
commitment and the two subscales of the hope measure (pathways: the ability to identify a means to achieve a goal; and agency: the capability to proceed along identified pathways). These results suggested that purpose commitment is a means by which a young person's identity is associated with positive outcomes (Burrow \& Hill, 2011). The researchers concluded that determining one's purpose in life is associated with selfaffirming behaviors, which, may lead to experiences that are more likely to be positive and satisfying (Burrow \& Hill, 2011).

Study I from the current research examined purpose commitment as a mediator of the relationship between identity and well-being among a sample of emerging adult Hispanic women in order to replicate and extend the work of Burrow and Hill (2011). Figure 1 presents the conceptual model that corresponds to Study I.

\section{Study II: Cultural Factors and Identity Commitment in Hispanic Women}

Study II further extended the work of Burrow and Hill (2011) by identifying cultural factors associated with identity commitment in this population. The current research focused on identity development among Hispanic women, who are likely influenced by cultural expectations. Owles (2009) found that the experience of immigration was associated with personal identity among a sample of Cuban American women, which corroborates with the existing literature on social influence and identity formation (Portes \& Rumbaut, 2006; Portes \& Stepick, 1994; Stepick et al., 2003).

In general, ethnic and cultural factors are important factors of self-definition among minorities and immigrants of multiple cultural backgrounds (Phinney \& Ong, 2007) such as the participants in the current research. Studies have also shown that the attitudes and beliefs associated with a Hispanic woman's ethnicity or culture of origin 
help to inform her self-concept (Miville, Koonce, Darlington, \& Whitlock, 2000; Phinney, 1996). An example of how a Hispanic woman's college experience can be associated with issues of ethnicity and culture is apparent in the pressure she may experience as she is encouraged to enroll in a college that is closer to her family of origin as opposed to one that is located far away (Lujan, 2008). Experiences such as these illustrate the influence of culture and gender on Hispanic women that is elucidated by the concept of marianismo (Stevens, 1973). Marianismo posits that gender role beliefs in traditional Hispanic culture espouse a behavior style that emphasizes self-abnegation, passivity, and a lack of independence from others (Gil \& Vasquez, 1996; Stevens, 1973).

Thus the purpose of Study II was to examine ego identity development among emerging adult Hispanic women. The culturally informed variables of marianismo, ethnic identity, and acculturation, were hypothesized to contribute to ego identity development among emerging adult Hispanic women. Figure 6 presents the conceptual model for Study II.

\section{Contributions to the Literature}

Despite the amount of literature on Erikson's model of ego identity development, there are few studies that apply the theory to cross-cultural samples (Kagitcibasi, 2007). There is a paucity of research that applies Eriksonian principles of identity development to youth from multicultural backgrounds (Diaz, 2004) despite the importance of identity development among ethnic minority youth (Phinney, 1992). Studies are needed which assess ego identity development among ethnic minority populations, especially Hispanics (Schwartz, Mason, Pantin, \& Szapocznik, 2009). According to Schwartz et al. (2009), researchers should examine Erikson's theory of identity among Hispanics and examine 
the generalizability of findings from non-Hispanic White populations to Hispanic populations (Schwartz, Côté, \& Arnett, 2005).

The current studies are expected to contribute to the existing literature in many ways. First, the studies contribute to the literature on identity development, which is a core developmental milestone for the emerging adult population. Research is needed to examine predictors of identity commitment and the relation of identity commitment to well-being (Ojeda, Navarro, Rosales Meza, \& Arbona, 2012). Second, the current studies address the gap in the literature identified by Stoddard and Garcia (2011), who emphasized the need for studies at the national and state level that examine the psychological well-being of Hispanic women. Third, the studies also inform the current research on Hispanic emerging adults enrolled in college, who are generally underrepresented in the literature (Rodriguez, et al., 2000). Fourth, the present research also addresses the need for further inquiry into the roles that cultural beliefs regarding gender roles, ethnic identity, and acculturation play in the formation of ego identity commitment and the relation between ego identity and well-being among young ethnic minorities (Aries \& Moorehead, 1989; Phinney \& Alipuria, 1990).

\section{Statement of the Problem}

The purpose of Study I was to examine the mediating effects of purpose on the relationships between identity commitment and the well-being outcomes of hope and life satisfaction among emerging adult Hispanic women. The purpose of Study II was to examine the relations of marianismo, ethnic identity, and acculturation to ego identity among emerging adult Hispanic women. These two related studies were designed to answer the following research questions. 


\section{Research Questions}

Study I. What is the nature of the relationships between ego identity commitment and purpose commitment (independent variables), and hope and life satisfaction (dependent variables) among emerging adult Hispanic women?

Study II. What is the nature of the relationships between marianismo, ethnic identity, and acculturation (independent variables) and ego identity commitment (dependent variable) among emerging adult Hispanic women? 


\section{LITERATURE REVIEW}

The following literature review first includes an overview of the research on the development and significance of ego identity commitment in adolescence and emerging adulthood. The literature relevant to Study I on identity, purpose, hope, and life satisfaction is reviewed first, followed by a review of the literature on marianismo, acculturation, and ethnic identity. The specific aims of the research are also presented.

\section{Identity Commitment}

The construct of identity is an integral part of the work by Erik Erikson (1950), who posited that a coherent ego identity provides the infrastructure for the development of a productive life course, describing ego identity as an individual's stable, coherent, and integrated sense of self (Erikson, 1968). Identity was also named in Erikson's (1968) psychosocial stages of development, which described adolescence as a time period where an individual must reconcile his or her tendencies towards identity achievement versus identity confusion. Ego identity formation is generally described in terms of exploration and commitment, with exploration denoting the consideration of multiple identity possibilities (Grotevant 1987), and commitment referring to the adoption of one or more such alternatives (Bosma \& Kunnen, 2001). Identity commitment refers to the degree of conviction regarding who one and his or her identification with a specific identity (Hill \& Burrow, 2012; Serafini \& Adams, 2002).

The work of Marcia (1966, 1980) built upon Erikson's (1964) understanding of identity by hypothesizing that a person's level of global identity is indicative of the level of evolutionary development of their ego (Branch, Tayal, \& Triplett, 2000). Marcia (1980) proposed the identity status model, which describes four statuses of identity 
development that illustrate various degrees of commitment: diffusion, foreclosure, moratorium, and achievement. When a person has not decided upon an identity and is not concerned by experiencing a lack of identity, that individual is in the diffused identity status (Branch, et al., 2000). Foreclosed identity status refers to a person who has committed to an identity that was determined by other people, whereas an individual who actively seeks an identity but has not formed a commitment to a definitive identity is in the moratorium identity status (Branch et al., 2000). An individual who has made a substantial commitment to a particular identity is understood to be experiencing the achieved identity status as outlined by Marcia's identity status model (Branch et al., 2000; Marcia, 1966).

Although opinions vary as to how people establish their identities (van Hoof \& Raaijmakers, 2003), ego identity formation is considered a process that heavily influences adult decisions such as marriage, career, and family (Fadjukoff, Pulkkinen, \& Kokko, 2005). Identity also serves as a social-psychological structure that assists in the process of self-regulation (Adams \& Marshall, 1996), particularly for young people. This is due in part to the association of identity-related difficulties with low self-esteem and self-destructive activities (Côté \& Levine, 2002; Côté \& Bynner, 2008).

Conversely, a well-defined ego identity is correlated with a number of positive outcomes (St. Louis \& Liem, 2005) such as self-esteem, scholastic success, moral reasoning, and adaptive mental functioning, as well as an internal locus of control, a reduced incidence of depression (Aries \& Moorehead, 1989; Cramer, 1995; Kroger, 2007; Marcia, 1980; Waterman, 1992), and lowered degrees of internalizing and externalizing symptoms (Schwartz, 2007). In their 1996 study, Miville and Helms applied 
the identity status model of identity development to a sample of 177 Hispanic women in order to examine the intersections of cultural, gender, and personal identity. All four identity status categories were associated with gender and cultural identity; specifically, identity achievement was associated with positive gender identity and positive cultural identity.

Study I addressed the extent to which findings regarding the association of identity commitment to well-being are applicable to emerging adult Hispanic women. Study II assessed cultural factors potentially related to identity commitment.

\section{Study I: Purpose as a Mediator of the Identity-Well-Being Relationship}

Study I of the current research is a replication of the 2011 work by Burrow and Hill, which examined the mediating effects of purpose commitment on the relations between identity commitment and the well-being outcomes of hope and life satisfaction. In a review of literature pertaining to Study I, the findings on purpose commitment as identity capital are presented first, followed by findings related to the outcome variables of hope and life satisfaction.

\section{Purpose Commitment}

Psychologists have long studied purpose in life as an internal motivating force (Frank1, 1963; Hayes, Strosahl, \& Wilson, 1999; Yalom, 1980). According to Damon (2008), purpose in life is an enduring and overarching objective towards an achievement that is not only personally salient, but also encourages a person to pursue situations that supersede self-interests (Damon et al., 2003; Damon, 2008).

Kashdan and McKnight (2009) offer an additional definition, which describes purpose as an aim in life that is central and self-organizing. A better understanding of the 
components to Kashdan and McKnight's definition of purpose helps develop a deeper understanding of the meaning behind the concept of purpose in life. According to Kashdan and McKnight (2009), purpose is considered central because it is highly influential in regards to identity, and self-organizing because it presents a paradigm that informs an individual's daily behavior. Furthermore, purpose is a life aim because it does not have a delimited end in and of itself. As such, it is something that cannot be obtained and continues to drive behavior. Thus the literature suggests that purpose in life exerts a substantial amount of influence on one's self-concept and direction in life.

Studies associated with positive psychology have most frequently examined the relations between purpose and thriving (Bronk et al., 2009). Victor Frankl's experience in the holocaust prompted him to propose that a strong sense of purpose is an asset that helps individuals to cope with difficulties that occur over the course of one's lifespan (Frankl, 1963). He also asserted that an individual's sense of purpose can be enhanced by encountering adverse situations (Ryff, Keyes, \& Hughes, 2003). Benson (2006) also reiterated the positive implications of life purpose by describing it as a developmental asset that is associated with flourishing (Seligman, 2002) and increased levels of subjective well-being (French \& Joseph, 1999). Purpose is likewise associated with increased psychological health among adults (Crumbaugh \& Maholick, 1964; Kish \& Moddy, 1989), and decreased mental distress (Debats, 1998). Youths with a sense of purpose are also more likely to exhibit psychological health than their peers (Shek, 1993).

Purpose and the identity capital model. The current research replicates the work of Burrow and Hill (2011), who applied the identity capital model to their study on emerging adults and hypothesized that purpose commitment can serve as a form of 
identity capital. As defined by Burrow and Hill (2011), purpose commitment refers to one's personal quest to engage with, identify, and determine the content of his or her life purpose, whereas identity capital is comprised of the aspects of one's personal identity that contribute to a stable sense of self and allow for adaptive decision-making. The identity capital model (Côté, 1996) applies a developmental-social psychological perspective to the process of identity formation, and was developed in order to better comprehend the mechanisms through which emerging adults can improve their capacity to function at college or in the workplace (Côté, 1996; 1997).

Identity capital can be classified as tangible or intangible (Côté \& Schwartz, 2002). Examples of tangible assets of identity capital include educational attainment, material goods, or membership in clubs or organizations, while examples of intangible forms of identity capital include one's personality characteristics, cognitive capabilities, self-efficacy, or critical thinking skills (Côté, 1996). Identity capital is particularly salient for emerging adults enrolled in college because the university setting offers many opportunities for development of both forms of identity capital (Côté, 1996).

Burrow and Hill (2011) proposed that the capital ensuing from establishing a stable sense of identity facilitates the development of self-directed goals enabling commitment to a purpose in life which, in turn, fosters personal well-being. A search of the relevant literature reveals no studies on the application of the identity capital model to Hispanic women. Following the work of Burrow and Hill (2011), the model tested in Study I examined the mediating effects of purpose commitment on the relationships between ego identity commitment and the well-being indicators of hope and life satisfaction among emerging adult Hispanic women. 


\section{Hope}

Hope has emerged within the literature as a topic of interest because of a current trend among researchers to explore positive psychology and related constructs (Arnau, et al., 2010). Hope demonstrates that an individual believes in tomorrow and has a positive association with future events (Hinds, 1984; Miller \& Powers, 1988). A person with high levels of hope feels capable of pursuing goals and can identify means by which these goals can be achieved (Snyder, Hoza, Pelham, Rapoff, Ware, \& Danovsky et al., 1997). Hope accompanies individuals as they pursue goals and helps to mitigate the burden of their earthly concerns (Smith, 1983). Other researchers (Arnau et al., 2010; Staats, 1987) posit that hope aligns with a person's desire for events yet to come and motivates her or his actions. Studies on positive psychology suggest that hope fortifies a person's character and is highly affected by one's cognitive state (Peterson \& Seligman, 2004). The field of positive psychology has classified hope as a character strength because of its effects on a person's behaviors, thoughts, and feelings (Park, Peterson, \& Seligman 2004; Seligman \& Csikszentmihalyi, 2000).

Although hope is related to self-efficacy (Bandura, 1982) and dispositional optimism (Scheier \& Carver, 1985), it is not to be confused with these concepts. Studies have shown that hope and self-efficacy differ in terms of expectancy (Magaletta \& Oliver, 1999). Efficacy expectancy is determined by the perception that one is able to accomplish a task, while hope expectancy involves the perception that one will in fact complete the task (Bronk et al., 2009). Hope differs from optimism in that hope is more specifically associated with individual goal achievement, whereas optimism refers to the overall anticipated nature of forthcoming events (Bryant \& Cvengros, 2004). 
Although several researchers have conceptualized hope in the literature (Pacico, Zanon, Bastianello, \& Hutz, 2011), it is C. R. Snyder's Hope Theory (1994) that has drawn the most attention among the psychology community (Snyder, Rand, \& Sigmon, 2002). According to Hope Theory, an individual's degree of agency serves as a catalyst of hope by cultivating a positive sense of goal achievement (Snyder et al., 1991). Furthermore, hope-agency refers to the capability to proceed along identified pathways, while hope-pathways refers to the ability to identify plans that are necessary in order to meet identified goals (Snyder et al., 1991). Therefore, agency indicates one's efficacy expectancy while pathways indicate one's outcome expectancy (Snyder et al., 1991). Optimism is more likely to correspond with hope-agency than hope-pathways (Snyder et al., 2001).

Despite the importance of the concept of hope in positive psychology, there is a lack of understanding regarding the experience of hope among ethnic minority populations, particularly among young Hispanics (Edwards, Ong, \& Lopez, 2007). Hispanic youth stand to benefit from the development of hope, because they are generally coming into adulthood at the same time that they are struggling with establishing a bicultural identity affected by both Hispanic and European American cultural influences (Phinney, Kim Jo, Osorio, \& Vilhjalmsdottir, 2005). Furthermore, Edwards et al. (2007) suggest that hope may serve as a protective factor for Hispanic youth, who can utilize their sense of hope agency and hope pathways in order to handle issues associated with biculturalism such as discrimination. In their 2007 study, Edwards et al. examined hope among a group of 135 Mexican youth. Results of their research indicate that the scores of Mexican youth on the Children's Hope Scale correlated positively with positive affect 
and support from friends and family, in addition to life satisfaction (Edwards et al., 2007). These results indicate that the scores of Mexican youth on the Children's Hope Scale supported the criterion validity of the construct, which suggests that hope may operate similarly among Hispanic youth as it does among non-Hispanic youth (Edwards et al., 2007).

\section{Life Satisfaction}

Diener et al. (1999) included life satisfaction in their definition of subjective well being, describing it as consisting of the emotions and environment-specific satisfactions combined with one's overall assessment of life satisfaction. More specifically, life satisfaction works in concert with an individual's emotional responses (i.e., positive and negative affect), and domain satisfactions (i.e., feelings of fulfillment associated with a person's career or interpersonal relationships; Diener et al., 1999). Although life satisfaction is considered a primary indicator of one's subjective well-being (Diener \& Diener, 1995), it is a necessary but not sufficient component. Life satisfaction encompasses the cognitive aspect of an individual's subjective well-being (Park et al., 2004), and supersedes the effects caused by an individual's mood state (Diener et al., 1999). Assuming that a person's basic needs are met, life satisfaction is generally associated with the successful realization of goals (Veenhoven, 2004), and beliefs about one's self (Diener et al., 1999; Leung \& Leung, 1992; Liebkind \& Jasinskaja-Lahti, 2000; Terry \& Huebner, 1995).

Furthermore, life satisfaction has been the focus of several studies that have demonstrated its associations with positive developmental outcomes such as self-esteem (Diener \& Diener, 1995), in addition to positive mood and resilience (Cohn, Fredrickson, 
Brown, Mikels, Conway, 2009; Gross \& John 2003). Life satisfaction is likely associated with goal attainment because attaining goals is associated with positive attributions of the self as well as increased overall satisfaction (Bradley \& Corwyn, 2004). Furthermore, life satisfaction has been associated with physical aspects of well being, such as increased life expectancy (Chida \& Steptoe, 2008).

Life satisfaction has been associated with outcomes similar to ego identity, including positive developmental indicators such as positive self-image, positive social relationships, and reduced problem behaviors (Luyckx, Goossens, Soenens, Beyers, \& Vansteenkiste, 2005; Zimmer-Gembeck, 2006). Hope has also been found to correlate with life satisfaction (Park et al., 2004), which in turn contributes to a person's level of general mental health (Burrow, Summer, \& Ong, 2013; Cummins \& Nistico, 2002) and happiness, also known as subjective well-being (Diener, 2000).

There is no lack of research on life satisfaction, but the majority of related studies have been performed on samples of individuals who are of European ancestry residing in Western cultures (Bradley \& Corwyn, 2004). Life satisfaction and its relation to an individual's experience may differ for members of different ethnic groups (Bradley \& Corwyn, 2004), as intrapsychic phenomena may serve as the foundation of life satisfaction among some cultures, whereas other cultures may consider social factors as forming the basis of life satisfaction (Suh, Diener, Oishi, \& Triandis, 1998). A person's internal tendencies are less emphasized within collectivist cultures as opposed to individualistic cultures (Morris \& Peng, 1994), the latter of which view the self as a separate entity that is less likely to be influenced by contextual and relational factors (Triandis, 1989). 
The literature on life satisfaction among Hispanics explores its correlations with related constructs. For example, Bradley and Corwyn (2004) studied perceived life satisfaction in a multiethnic sample that included 48 Mexican Americans. Among the Mexican Americans in this sample, life satisfaction was positively associated with selfefficacy (Bradley \& Corwyn, 2004). In their 2012 study, Ojeda et al. examined the relation between demographic variables and life satisfaction in a sample of 115 Latino college students, 87 of whom were women. Results from their inquiry suggested that men experienced higher levels of life satisfaction than women. The authors suggested that the observance of traditional Hispanic gender roles (such as those described by marianismo) may influence the experience of life satisfaction among the Hispanic women in their sample (Ojeda et al., 2012).

In sum, the literature suggests that personal identity commitment, commitment to a life purpose, hopefulness, and life satisfaction are important components of positive development in emerging adulthood. However, only one study (Burrow and Hill, 2011) has established the interrelations among these indicators. Research on these aspects of positive development in emerging adult Hispanics has been limited and, prior to the current study, there has been no replication of the Burrow and Hill research with a Hispanic population.

\section{Study II: Marianismo, Ethnic Identity, Acculturation}

In Study II, marianismo, ethnic identity, and acculturation were examined as predictors of ego identity commitment among emerging adult Hispanic women. The literature relevant to each of these areas is reviewed in this section. 


\section{Marianismo: Traditional Hispanic Gender Role Beliefs}

Research suggests that culture predicts mental health outcomes among Hispanic college students (Ojeda, Flores, \& Navarro, 2011) and recent studies have aimed at a better understanding of the role that Hispanic gender values have on mental health outcomes (e.g., Castillo, Perez, Castillo, \& Ghosheh, 2010). Hispanic culture maintains traditional beliefs concerning gender roles (Castillo \& Cano, 2008), and is heavily influenced by a patriarchal structure that restricts women from independently developing their views on gender role behaviors (Arredondo, 2002). Conflict may arise for Hispanic women who are pursuing a college degree because they may not conform to traditional values regarding gender role behaviors, especially if career aspirations are prioritized over family interests (Castillo et al., 2010; Marano, 2000).

Marianismo (Stevens, 1973) is a concept that depicts the traditional gender role beliefs within traditional Hispanic culture that define a woman's role in regards to her relationships, family, and career (Castillo et al., 2010). Marianismo is a reflection of the rigid patriarchal structure that permeates Hispanic society and consequently limits the impact and influence of women (Arredondo, 2002). According to the marianismo construct, a Hispanic woman may only experience her power within the confines of her role as a wife and a mother to someone else (Lavrin, 2004; Rocha-Sanchez \& DiazLoving, 2005). Although a Hispanic woman in college might view marianismo differently than a woman who is less educated (Castillo et al., 2010), she may still face scrutiny from members of her own ethnic group if she decides to reject these beliefs (Niemann, 2001), 
In their 1996 work, Gil and Vazquez identified the "Ten Commandments of Marianismo," namely that a traditional Hispanic woman should not: 1) forget her place, 2) forsake tradition, 3) be independent, 4) put her needs first, 5) engage in sex for pleasure, 6) be more than a housewife, 7) get angry at her husband, 8) ask for help, 9) change, or 10) discuss personal problems outside the home (p. 6). These commandments illustrate marianismo in its "purest, darkest form" (Gil \& Vasquez, 1996), and the tenets of marianismo can affect a Hispanic woman's ability to obtain self-validation (Cano, 2003). At its extreme, the characteristics of marianismo produce two archetypes, the namely the "fallen woman" and the highly esteemed woman or maternal figure (RiveraMarano, 2000).

The characteristics portrayed in marianismo describe behavior that is passive, dependent and self-effacing (Kulis et al., 2008) and marianismo has been linked to depressive symptoms. For example, Cano (2003) examined acculturation, marianismo and depression among a sample of 122 undergraduate Mexican American women. Results from this research indicated that marianismo accounted for approximately $11 \%$ of the population variance with regards to depression. Therefore, higher endorsement of marianismo beliefs among women in this sample was associated with higher levels of depression. Jezzini (2013) also found that levels of marianismo were associated with depressive symptoms. Additional studies have shown that traditional gender role behaviors such as those espoused by marianismo are positively related to depression (Nieves-Squires, 1991) and other negative outcomes such as intimate partner violence and HIV/AIDS (Moreno, 2007). 


\section{Acculturation}

Acculturation is a process that takes place as an individual experiences repeated contact between two distinct cultures (Berry, Trimble, \& Olmedo, 1986). It is a societal variable (Caldera et al., 2003) in the form of a multidimensional process during which an individual adapts to a receiving culture that differs from his or her native culture (Berry, 1980). Acculturation occurs as a person alters aspects of his or her social presentation in order to appear more similar to members of another culture (Ojeda et al., 2012), although a person's sense of identity can serve to "anchor" the individual who is undergoing the process of acculturation (Schwartz et al., 2006). Thus, the individual engages in the acculturation process by adopting new behaviors (Rogler, Cortes, \& Malgady, 1991) from the receiving culture and retaining beliefs and principles from her or his native culture (Phinney, Horenczyk, Liebkind, \& Vedder, 2001). For Hispanics, this can entail using Spanish as well as English to communicate or altering an individual's social relations to reflect a larger influence of Hispanic culture (Caldera et al., 2003).

The existing literature offers suggestions that individuals who are engaging in the acculturation process may experience stress as a result of inhabiting different worlds (Ojeda et al., 2012). Thus acculturative stress may result in feelings of detachment from members of their ethnic group (Ginorio, Gutiérrez, Cauce, \& Acosta, 1995) as well as members of the college community (Gloria \& Pope-Davis, 1997). In a study by Romero and Roberts (2003), depressive symptomatology was associated with bicultural stress, or stress from belonging to more than one cultural group. Both minority status stress (stress resulting from ethnic minority status (Saldaña, 1994) and acculturative stress (stress 
associated with the process of acculturation (Rodriguez, Myers, Morris, \& Cardoza, 2000) have been associated with psychological distress.

However, individuals that are comfortable engaging with both their native and host cultures appear to fare better than those who are not. In a study by Berry, Phinney, Sam, and Vedder (2006), integration of both cultures was found to be associated with psychological and sociological adaptation. Furthermore, a recent study of immigrant college students by Schwartz et al. (2013) addressed the association between acculturation and personal identity more directly. Students classified as identity achieved (committed) scored higher on measures of acculturation to both their native and host cultures, which is consistent with the view that bicultural competence is personally adaptive.

The four-fold model of acculturation. One of the most prominent theories of acculturation is the model proposed by Berry (1998). According to the theory, acculturation takes place across four forms, namely Assimilation, Integration, Separation, and Marginalization (Berry, 1980). Assimilation occurs when an individual alters his or her cultural orientation to reflect the receiving culture, in place of a previously held orientation to that person's native culture (Berry, 1998). Integration, also known as Biculturalism, represents a combination of beliefs from both the receiving culture and the native culture, while Separation indicates sole retention of native culture orientations (Berry, 1998). Marginalization is associated with alienation from orientations associated with both the receiving culture and the native culture (Berry, 1998).

Although the model of acculturation proposed by Berry (1998) has heavily influenced the literature on acculturation, there are some shortcomings of this 
perspective. Some of the strongest arguments against the fourfold model have been posited by Unger at al. (2007), who suggest that acculturation is not a linear process and the adoption of aspects from the receiving culture does not necessitate a loss of influence from one's native culture (Rudmin, 2003; Unger et al., 2007). In addition, the fourfold model does not account for individual variance with respect to the acculturation process because an individual's acculturation pattern is subject to multiple influences, such as perceived norms and factors that are specific to the situation at hand (Unger et al., 2007).

Moreover, the fourfold model has been criticized because it assumes that the receiving culture is comprised of a singular majority culture (Unger et al., 2007), which is infrequently the case in our modern globalized society. The fourfold model also assumes that the four patterns are mutually exclusive, even though several studies indicate that they are intercorrelated (Rudmin, 2003; Unger et al., 2007). Despite the substantial influence of the fourfold model on acculturation theory, its shortcomings allow for improvements to be made regarding future models of acculturation processes. The current research employs a bidimensional measure of acculturation (as defined below) that assesses acculturation to American culture and acculturation to (i.e., retention of) Hispanic culture separately.

Unidimensional vs. bidimensional measures of acculturation. Although a substantial amount of research has examined acculturation among Hispanics, fewer studies have focused on how to best measure the process associated with acculturation (Unger et al., 2007). For the most part, measures that examine acculturation are generally classified as unidimensional or bidimensional (Unger et al., 2007). Unidimensional measures seek to place the participant on a continuum from the native culture to the 
receiving culture by applying a zero-sum paradigm to the acculturative process, such that an instrument measuring acculturation from Mexico to the United States might employ a scale ranging from exclusively Spanish to exclusively English and include both cultures within the same item on the survey (Unger et al., 2007).

Bidimensional measures assess for identification with native culture and receiving culture by treating the two categories as mutually exclusive (Unger et al., 2007). Therefore, a bidimensional scale measuring acculturation among Mexican-Americans would posit questions regarding levels of identification with Mexican culture and United States culture separately and would not assess for influence of both cultures in the same questionnaire item (Unger et al., 2007). The current study uses data from the Multidimensional Measure of Cultural Identity Scales for Latinos (MMCISL; Félix-Ortiz, Newcomb, \& Myers, 1994), a bidimensional measure of cultural identity that has been developed specifically for use with Hispanics.

Cultural identity. Acculturation informs an individual's sense of identity. A person's degree of acculturation stems from their social and cultural identity (Schwartz et al., 2006). Cultural identity is a unique form of social identity that is defined by a person's coalescence with his or her cultural context (Bhatia \& Ram, 2001; Padilla \& Perez, 2003; Phinney et al., 2001). The values and behaviors that comprise an individual's cultural identity represent specific ideals and beliefs that are unique to that particular culture and may include constructs such as collectivism, familism, and filial piety (Jensen, 2003). Cultural identity is likewise associated with a feeling of solidarity with the principles of a specific cultural group along with the values and behaviors 
directed toward one's own culture in response to this solidarity (Jensen, 2003; Roberts, Phinney, Masse, Chen, Roberts, \& Romero, 1999).

However, a person's cultural identity may change because the acculturation process may prompt the individual to reexamine her or his core beliefs, choice of language, and views on the importance of the individual relative to the group (Schwartz et al., 2006). Additionally, the notion of an "ingroup" may grow to include individuals from the receiving culture, who may no longer be classified as members of an "outgroup" (Schwartz et al., 2006). Therefore, professionals who work with Hispanic adolescents must improve their understanding of acculturative processes in addition to the development of appropriate measures of acculturation (Unger, et al., 2007).

Some relations between cultural identity and ego identity commitment have been found. Miville and Helms (1996) studied the relationship between ego identity and cultural identity among Hispanics of Central American, South American, or Cuban origin. The results of their study demonstrated that cultural resolutions were mirrored in their ego identity, such that commitment to cultural identity predicted ego identity commitment (Miville and Helms, 1996). Similar findings were discovered in a 2000 study on Mexican Americans, which demonstrated that commitments associated with ego identity were likewise associated with resolution of cultural identity themes (Miville et al., 2000).

\section{Ethnic Identity}

Ethnic identity exploration often coincides with the process of acculturation and is a key developmental task during adolescence (Spencer \& Markstrom-Adams, 1990). There is conceptual overlap between the concepts of cultural identity and ethnic identity, 
although the literature on adolescent and emerging adult development has focused more on ethnic identity. Ethnic identity is defined as one's sense of "self-identification, feelings of belongingness and commitment to a group" (Liebkind, 2006, p. 80). Along with marianismo, a Hispanic woman's ethnic identity is likely to contribute to her sense of ego identity (Phinney \& Alipuria, 1990).

However, ethnic minorities may experience damage to their self-image and selfrespect (Tajfel, 1981) that is associated with perceived discrimination (Phinney, 1990). Additional stressors associated with ethnic minority status include pressure to conform to one's own-group and preoccupation with confirming a stereotype (Phinney, 1996). Young people with a strong ethnic identity tend to develop a more profound sense of purpose and meaning in life, which can lead to adaptive functioning (Kiang \& Fuligni, 2010) and emotional well-being (Branscombe, Schmitt, \& Harvey, 1999).

Conflict with respect to one's cultural identity has been associated with crises of ego identity (Miville et al., 2000). St. Louis and Liem (2005) found that both majority and minority college students who have not made concrete commitments with respect to their ego identity are more likely to have not fully explored their association with a particular ethnic group. Thus an individual who exhibits a lack of ethnic identity commitment is subsequently more likely to experience a lack of ego identity commitment (St. Louis \& Liem, 2005).

Jean Phinney (1989) applied a developmental perspective to ethnic identity formation by positing that an individual who commits to and learns about his or her ethnic group is likely to reject negative and stereotypical views. Phinney (1992) has 
demonstrated that ethnic identity formation is associated with the development of positive psychosocial adjustment among young members of ethnic minority groups.

Other researchers have suggested that studies examining identity should include multiethnic samples (Sneed, Schwartz, \& Cross, 2006), while Schwartz, Zamboanga, Weisskirch, \& Rodriguez (2009) have underscored the need to study ethnic and cultural identity alongside personal identity. Gamst et. al (2002) have suggested that studies on ethnic identity in young adults should include related concepts such as acculturation and gender roles (Gamst et al., 2002). The current research follows that suggestion.

\section{The Current Studies}

The current research involved two studies focused on ego identity commitment in emerging adult Hispanic women. The literature has indicated, commitment to a personal identity is considered to be a primary developmental task for emerging adults (Erikson, 1968). The establishment of a positive identity is associated with personal well-being (Meeus, Iedema, Helsen, \& Vollebergh, 1999). A seminal study by Burrow and Hill (2011) found that commitment to a life purpose mediated the effects of identity commitment on two well-being indicators, hope and life satisfaction, in a Midwestern U.S. sample of emerging adults, but whether these findings would generalize to a Hispanic population has not been determined.

As noted, the literature also suggests that a focus on personal identity and individual goal pursuits (as in pursuit of purpose) may fit more with individualistic cultures valuing personal autonomy than with collectivist cultures valuing group cohesion (Kagitcibasi, 2007). Thus, it is important to address how cultural factors may relate to identity commitment. Hispanic women are of particular interest in this regard, as the 
value placed on traditional gender roles requiring women to be self-effacing and devoted to family, as embodied in the concept of marianismo, might be expected to work against developing a strong ego identity. Some research has suggested that acculturation and ethnic identity are additional cultural factors that may affect personal identity commitment among emerging adults with immigrant backgrounds.

The current research consisted of two studies extending the Burrow and Hill (2011) research to a sample of emerging adult Hispanic women college students. Study I assessed the extent to which the original Burrow and Hill findings would generalize to a Hispanic female sample. Study II addressed cultural factors potentially contributing to ego identity commitment among emerging adult Hispanic women, including marianismo, ethnic identity, and acculturation. On the basis of the existing literature, two research questions were posed:

1. What is the nature of the relationships between ego identity commitment and purpose commitment (independent variables), and hope and life satisfaction (dependent variables) among emerging adult Hispanic women? (Study I)

2. What is the nature of the relationships between marianismo, ethnic identity, and acculturation (independent variables) and ego identity commitment (dependent variable) among emerging adult Hispanic women? (Study II)

Specific hypotheses associated with each research question are delineated in the following sections. Study I hypotheses are presented first, followed by hypotheses developed for Study II. 


\section{Study I Hypotheses: Identity, Purpose, and Well-Being}

Study I of the current research is a replication of Burrow and Hill (2011) which examined well-being as an outcome and assessed for the mediating effects of purpose on the relationship between identity and well-being among emerging adult college students. The hypotheses to be tested for the present study were taken from the findings of Burrow and Hill, to ascertain whether results from that study regarding identity processes could be generalized to the current sample of Hispanic women. Thus, the following relationships were hypothesized for Study I.

Hypothesis 1-A: Identity commitment, purpose commitment, hope, and life satisfaction were hypothesized to exhibit positive intercorrelations.

Hypothesis 1-B: Purpose commitment was hypothesized to fully mediate the relationship between identity commitment and both the agency and pathways subscales of hope.

Hypothesis 1-C: Purpose commitment was hypothesized to partially mediate the relationship between identity commitment and life satisfaction.

\section{Study II Hypotheses: Marianismo, Ethnic Identity, and Acculturation}

Study II of the current research examined cultural factors predictive of identity commitment. The effects of marianismo, ethnic identity, and acculturation on ego identity commitment were examined. Past research has suggested that adherence to traditional gender role beliefs, as embodied in the concept of marianismo, has negative consequences such as depression and susceptibility to intimate partner violence that are likely associated with difficulties establishing a solid ego identity. Conversely, developing a strong ethnic identity has been associated previously with personal identity 
commitment. Finally, Schwartz et al. (2013) found bicultural acculturation reflecting facility with and appreciation of both American and Hispanic culture was linked to personal identity achievement. Therefore, the following hypotheses were proposed for Study II.

Hypothesis 2-A: Marianismo was hypothesized to be negatively associated with ego identity commitment.

Hypothesis 2-B: Ethnic identity resolution was hypothesized to be positively associated with identity commitment.

Hypothesis 2-C: Acculturation, as indexed by Spanish language proficiency, English language proficiency, familiarity with Latino culture, and familiarity with American culture, was hypothesized to be positively associated with ego identity commitment. 


\section{METHODOLOGY}

\section{Participants}

A convenience sample of 532 female Hispanic college women $\left(M_{\mathrm{age}}=20.60\right.$ years, $S D=1.80$, range $=7$ ) was recruited through the Department of Psychology subject pool, known as Sona Systems. Students who participated in the research earned extra credit for their participation. Inclusion criteria for the study were that the participant must be female, self-identify as Hispanic, and be between 18 and 25 years of age. The top five nationalities associated with the current sample were Cuban (42.8\%), Colombian (8.9\%), Puerto Rican (7.5\%), Nicaraguan (7.3\%), and Peruvian (5.5\%), with 28\% percent of the current sample reporting other nationalities. The percent of the sample born outside of the United States was 35\%. Eighty three percent of the sample reported that their mothers were born outside of the United States and $84 \%$ reported that their fathers were born outside of the United States.

\section{Procedures}

Participants completed an online survey through the University's Qualtrics survey program. Approval for the study was obtained from the Institutional Review Board at Florida International University. Prior to beginning the survey, students were shown a screen containing a Consent Form and asked to click a link acknowledging their consent to participate in the study. Students had the option to either give consent or leave the study and return to the list of available studies. Once consent was received, participants were able to complete the measures anonymously.

After completion of the survey, participants were directed to an entirely separate survey where they were asked to enter their name, student ID number, and age in order to 
receive credit for their participation. In order to allow for anonymity, the questions containing participants' identifying information were not linked to the survey used in the current study. The data were then exported to an SPSS data file on a computer with a login and access code known only to the Principal Investigator.

\section{Measures}

\section{Inclusion information}

Participants were asked to report demographic information for the purpose of determining their eligibility for the current studies, as per the inclusion criteria of age (18-25), gender (female) and ethnicity (Hispanic). Data from participants whose selfreported age, gender, and Hispanic ethnicity met these criteria were included in the analyses for Study I and Study II.

\section{Ego Identity Process Questionnaire (Studies I and II)}

The Ego Identity Process Questionnaire (EIPQ; Balistreri et al., 1995) measures identity status by capturing the building blocks of identity formation of commitment and exploration on a global process level and on an intermediate content level (Kroger, 2003). Instead of relying entirely on Marcia's model (Kroger, 2003), the EIPQ aims to measure the process associated with identity status among multiple areas of functioning (Balistreri et al., 1995; Kroger, 2003).

In his 2002 study, Schwartz assessed the convergent validity between the EIPQ and the global identity statuses of the Extended Objective Measure of Ego Identity Status, revised (EOM-EIS-II; Bennion \& Adams, 1986). Results indicated that Identity Commitment was positively related to Identity Achievement, unrelated to Identity Foreclosure, and strongly negatively related to Identity Moratorium (Schwartz, 2002). 
Berman, Schwartz, Kurtines, \& Berman (2001) found a moderate to high convergence between the EIPQ and the identity styles outlined by the revised Identity Style Inventory (ISI; Berzonsky, 1992). Commitment had a moderate positive correlation with Informational identity style, a strong positive correlation with Normative identity style, and a moderate negative association with the Diffuse/Avoidant style (Berman et al., 2001).

The EIPQ is a self-administered 32-item summated rating scale, with scores ranging from 16 to 96 . Twenty items of the questionnaire are positively worded and 12 items are negatively worded (Luyckx, Goossens, Soenens, \& Beyers \& 2006), all of which are spread over two subscales (Commitment and Exploration) and eight domains. The domains are classified as ideological or interpersonal, with ideological domains consisting of politics, religion, occupation and values, and interpersonal domains consisting of friendships, dating, gender roles, and family. The response scale is a 6-point Likert-like scale with responses ranging from "strongly agree" to "strongly disagree." Sample items include "I have never questioned my career goals," and "My beliefs about dating are firmly held." A higher score on the Ego Identity Process Questionnaire indicates the presence of higher levels of ego identity.

Luyckx et al. (2006) examined the factor structure of the EIPQ in a study on 775 college students from the Dutch-speaking area of Belgium. The study yielded a model containing two process factor subscales, namely Exploration and Commitment (Luyckx, et al., 2006). Both subscales demonstrated good internal consistency reliability, with Cronbach alpha levels of .70 and .72 for the 15 -item Commitment subscale and 13-item Exploration subscale, respectively. The current study used the Commitment subscale, 
which has yielded a reported Cronbach's alpha of .75 (Balistreri et al., 1995), which was repeated in the current study $(\alpha=.75)$.

\section{Study I Measures}

Revised Youth Purpose Survey. The Revised Youth Purpose Survey (YP; Bundick et al., 2006) was constructed by borrowing from related measures of purpose and meaning in life (i.e., Crumbaugh \& Maholick, 1964; Keyes, Smotkin, \& Ryff, 2002; Steger, Frazier, Oishi, \& Kaler, 2006). Its aim is to measure commitment to a life purpose, exploration of purpose (Bundick et al., 2006), and different types of purpose as indicated by college students (Mariano, 2007). The YP survey is a self-administered measure that was designed for use on adolescent and emerging adult populations, in which a higher score indicates the presence of high levels of life purpose. In addition to measuring different types of purpose, the YP was developed to assess the challenges and supports associated with these purposes (Mariano, 2007).

The current study used the Commitment subscale of the YP survey, which assesses for a commitment to an identified purpose. Previous research by Burrow, O’Dell and Hill (2010) has shown that purpose commitment is positively correlated with identity commitment and hope. Fifteen items are scored on a 7-point Likert-type scale ranging from "strongly disagree" to "strongly agree," with a higher score indicating a higher level of purpose commitment. Sample items include "My life has a clear sense of purpose" and "I do many things that give my life meaning." The YP survey has demonstrated reliability and predictive validity with adolescent samples (Bronk et al., 2009; Burrow et al., 2010). Reported Cronbach's alpha for the Commitment subscale is .81 (Burrow \& 
Hill, 2011). The current sample yielded a Cronbach's alpha of .86 for the Commitment subscale of the Youth Purpose Survey.

Hope Scale. The Snyder Hope Scale (HS; Snyder et al., 1991) was created according to a goal-setting framework. Hope is hypothesized to consist of agency and pathways, which operate as two interrelated cognitive attributes (Snyder et al., 1991). Agency refers to an individual's belief that he or she can successfully achieve one's goals, while pathways refers to an individual's self-perceived capacity to outline the means by which to achieve said goals (Snyder et al., 1991). The Hope Scale consists of 12 self-report items that are assessed on a 4-point Likert-type scale ranging from "definitely false" to "definitely true", with the two subscales consisting of four items each, and four items serving as fillers. The Agency subscale consists of four items that measure an individual's determination with respect to goals. A sample item from the Agency subscale is "My past experiences have prepared me well for the future." The Pathways subscale consists of four items that measures an individual's self-perceived capacity to discover several means to achieve a goal. A sample item from the Pathways subscale is "There are lots of ways around any problem."

The Hope Scale has shown positive correlations with optimism, perception of personal control, and self-esteem (Irving et al., 1990), and negative correlations with psychological disturbances (Schrank, Stanghellini, \& Slade, 2008). A high score on the Hope Scale indicates the presence of high levels of hope. The concurrent validity of the Hope Scale was established (Gibb, 1990), when used in conjunction with other scales that were hypothesized to correlate moderately with hope. Reported standardized Cronbach's alpha values are .73 for the Agency subscale and .61 for the Pathways subscale (Burrow 
\& Hill, 2011). Cronbach's alpha values for the current sample were .68 for the Pathways subscale and .78 for the Agency subscale.

Satisfaction With Life Scale. The Satisfaction With Life Scale (SWLS; Diener, Emmons, Larsen, \& Griffin, 1985) was developed as a brief but reliable measure of global life satisfaction as a cognitive and judgmental process (Diener et al., 1985). The SWLS was designed to address the need for a life satisfaction measure that was free of researcher bias and consisted of more than one item. The SWLS consists of five items that are averaged, with higher scores indicating more overall life satisfaction (Diener et al., 1985). Participants responded to self-report items on a seven-point Likert-type scale ranging from "strongly disagree" to "strongly agree". Sample items include "The conditions of my life are excellent," and "I am satisfied with my life."

The SWLS does not tap related constructs such as positive affect or loneliness (Diener et al., 1985). Convergent validity of the SWLS is supported by significant correlations between the SWLS and other common measures of well-being (Diener et al., 1985). Scores on the SWLS have shown slightly positive correlations with personality traits and significantly positive correlations with measures of subjective well-being (Diener et al., 1985). The measure has shown high temporal reliability and internal consistency (Diener et al., 1985); its internal consistency has been demonstrated with an alpha coefficient of .87 (Diener et al., 1985). Cronbach's alpha for the current sample was .90 .

\section{Study II Measures}

Marianismo Beliefs Scale. The Marianismo Beliefs Scale (MBS; Castillo, et al., 2010) is predicated on beliefs associated with gender role behaviors ascribed to women 
that are associated with traditional Hispanic culture (e.g., women are submissive, women should sacrifice for their family, women should be virginally pure and nonsexual). The measure consists of 24 items and uses a 4-point Likert-like scale of "strongly agree" to "strongly disagree." Sample items include "A Hispanic woman must be a source of strength for her family" and "A Hispanic woman should be pure." Higher scores on the Marianismo Beliefs Scale indicate higher levels of beliefs endorsed by marianismo. Research has supported convergent and discriminant validity of the MBS in a sample of 370 Hispanic university students (Castillo et al., 2010). Reported internal reliability for the scales ranged from .77 to .85 . Cronbach's alpha for the Marianismo Beliefs Scale has been reported at .85 (Piña-Watson, Castillo, Ojeda, \& Rodriguez, 2013). Cronbach’s alpha for the current sample was .93 .

Multidimensional Measure of Cultural Identity Scales for Latinos. The Multidimensional Measure of Cultural Identity Scales for Latinos (MMCISL) (FélixOrtiz et al., 1994) measures Hispanic and American cultural identity in areas such as language, behaviors and values. The measure was evaluated and validated for use with an adult population (Dillon, Félix-Ortiz, Rice, De La Rosa, Rojas, \& Duan, 2009). The MMCISL's psychometric properties were studied by Dillon et al. (2009) and the findings support the factor structure and psychometric properties of the measure with an adult population. The MMCISL has also demonstrated good reliability and validity among a sample of Hispanic mothers and daughters (Dillon et al., 2009).

The current study used the English Proficiency, Spanish Proficiency, Familiarity with American Culture, and Familiarity with Latino Culture subscales in order to assess level of acculturation. Sample items include "How well do you read Spanish?" (Spanish 
Proficiency), "How well do you read English?" (English Proficiency), "How familiar would you say that you are with fine art and fine artists of your Latin American country?" (Familiarity with Latino Culture), and "How familiar would you say that you are with history and politics of the United States?" (Familiarity with American Culture). The Spanish Proficiency and English Proficiency subscales used three items on a 4-point Likert scale ranging from "not at all" to "excellent" with higher scores indicating higher language proficiency. The Familiarity with American Culture and Familiarity with Latino Culture subscales used four items on 4-point Likert scale ranging from "I don't know anything about these" to "I know a lot about these" with higher scores indicating higher levels of familiarity. Reported Cronbach's alphas for the subscales are: .88 (Spanish Proficiency), .91 (English Proficiency), .77 (Familiarity with Latino Culture), and .69 (Familiarity with American Culture; Félix-Ortiz, Newcomb, \& Myers, 1994). Cronbach's alphas for the current study are: .89 (Spanish Proficiency), .92 (English Proficiency), .80 (Familiarity with Latino Culture), and .76 (Familiarity with American Culture).

Ethnic Identity Scale. The Ethnic Identity Scale (EIS; Umaña-Taylor, Yazedjian, \& Bámaca-Gómez, 2004) assesses for affirmation, exploration, and resolution related to ethnic identity. Studies using samples of college students and Hispanics have utilized and validated the EIS (St. Louis \& Liem, 2005; Umaña-Taylor \& Updegraff, 2007; UmañaTaylor, Vargas-Chanes, Garcia, \& Gonzales-Backen, 2008), which differentiates itself from other ethnic identity surveys by measuring an individual's process of defining their own ethnic identity (Umaña-Taylor et al., 2004).

Items from the Ethnic Identity Survey measure participants' feelings regarding ethnic identity and their level of engagement in activities related to ethnic identity (Lara, 
2009). Seventeen items are distributed among Affirmation, Exploration and Resolution subscales. All items are assessed on a 4-point scale ranging from "Does not describe me at all" to "Describes me very well." Higher scores on the Ethnic Identity Scale indicate a higher presence of beliefs associated with ethnic identity (stronger identification with one's ethnicity). The current study used the Resolution subscale, which has a reported Cronbach's alpha of .92 (Umaña-Taylor et al., 2004). Chronbach's alpha was .88 in the current study.

\section{Data Analytic Plan}

Descriptive statistics were obtained and evaluated using the SPSS computer package. Patterns of distributions were assessed for outliers and multiple peaks in distributions (Hartwig \& Dearing, 1979). Pearson bivariate correlations among the variables of interest were also obtained using the SPSS program. Structural models were specified for the hypothesized relations among the variables in Studies I and II (Figures 1 and 6). Analyses of effects were performed using robust estimators available in the computer program Mplus 5.0 (Muthén \& Muthén, 1998-2010). Goodness of model fit was assessed using standard indicators available through the Mplus program. 


\section{RESULTS}

\section{Preliminary Analyses}

Preliminary analyses were undertaken to assess distributional characteristics of the measures and to identify potential outliers. Multivariate outliers were identified by examining leverage indices for each individual, defining an outlier as a leverage score four times greater than the mean leverage (Wilcox, 2012), although no outliers were found.

Univariate indices of skewness and kurtosis were within acceptable range (see Tables 1 and 5 for Study 1 and Study II measures respectively) with the exception of English language proficiency $($ skewness $=-3.37$, kurtosis $=14.38)$, which was attributable to the sample being US college students who are likely to be high in English proficiency. The modeling included Maximum Likelihood Estimators (MLR) and bootstrapping with 2000 model iterations. MLR is robust to non-normality and nonindependence of observations and bootstrapping yields more stable estimates of effects with non-normal data. Bootstrapping is a statistical procedure that is recommended for the analyses of significance levels for indirect effects (Schumacker \& Lomax, 2010).

\section{Study I: Identity Commitment, Purpose Commitment, and Well-Being}

The objective of Study 1 was to replicate the 2011 study by Burrow and Hill, which examined purpose as a form of identity capital. Table 1 presents the descriptive statistics for identity commitment, purpose commitment, hope, and life satisfaction.

\section{Hypotheses Testing}

Three hypotheses were proposed for Study 1 in order to replicate Burrow and Hill (2011): Hypothesis 1-A was that the independent variables (identity commitment and 
purpose commitment) and the dependent variables (hope and life satisfaction) would be positively correlated with each other. It was also hypothesized that that purpose commitment would mediate the effect of identity commitment on well-being, as measured by hope and life satisfaction. In order to replicate the work of Burrow and Hill (2011), purpose commitment was hypothesized to fully mediate the relations between identity commitment and hope-agency and hope-pathways (Hypothesis 1-B) and to partially mediate the relation of identity commitment to life satisfaction (Hypothesis 1C). The hypotheses were tested using Pearson correlation coefficients (Hypothesis 1-A) and structural equation modeling (SEM) analyses (Hypotheses 1-B and 1-C). Results for each hypothesis are described below.

Hypothesis 1-A. Identity commitment, purpose commitment, hope, and life satisfaction were hypothesized to correlate positively with one another. Table 2 presents the correlation coefficients for the Study I variables. As anticipated, identity commitment, purpose commitment, hope-pathways, hope-agency, and satisfaction with life were positively intercorrelated, thus supporting Hypothesis 1-A.

Cohen's (2003) conventions for magnitude of correlations were applied in order to assess the strengths of the correlations. Hope-pathways and identity commitment were slightly correlated $(r=.198, p<.001)$, indicating that an increase in hope-pathways was associated with a slight increase in identity commitment. Correlations among the following variables were moderate: life satisfaction and hope-pathways $(r=.350, p<$ $.001)$; hope-agency and identity commitment $(r=.441, p<.001)$; life satisfaction and identity commitment $(r=.367, p<.001)$ and hope-pathways and purpose commitment $(r$ $=.311, p<.001)$, indicating that increases in one of these variables corresponded to a 
moderate increase in the other variable. The following variables were strongly correlated: life satisfaction and hope-agency $(r=.508, p<.001)$; hope-pathways and hope-agency $(r$ $=.609, p<.001)$; and life satisfaction and purpose commitment $(r=.519, p<.001)$, indicating that as the levels of one variable increased, levels of the other variable were highly likely to increase.

Structural Equation Analyses: Hypotheses 1-B and 1-C. Purpose commitment was hypothesized to fully mediate the relation between identity commitment and both subscales of hope (1-B) and to partially mediate the relation between identity commitment and life satisfaction (1-C). The structural model representing these hypotheses is described in Figure 1 and was evaluated using robust estimators obtained in the computer program Mplus 5.0 (Muthén \& Muthén, 1998-2010). Following the recommendations of Bollen and Long (1993), a variety of global fit indices were used to evaluate the fit of the model to the data. Results of model analysis using Structural Equation Modeling indicate good model fit $\left(X^{2}=0.647(1), p=.421 ; \mathrm{CFI}=1.000\right.$; RMSEA $=0.000 ;$ SRMR $=.009$ ). Inspection of the residuals and the modification indices revealed no significant points of ill fit. Results of the analysis are presented in Tables 3 and 4 and depicted in Figures 2 through 5.

As can be seen in Table 3 and Figure 2, purpose commitment was positively associated with all other variables of interest. Identity commitment and purpose commitment had the strongest relationship $(\beta=.708, p<.001)$, such that for every one standard deviation increase above the mean in identity commitment there was an increase in purpose commitment of .708. Purpose commitment was associated with hopepathways $(\beta=.043, p<.001)$, such that for every one standard deviation increase in 
purpose commitment there was a .043 increase in hope-pathways. Purpose commitment was also associated with hope-agency $(\beta=.055, p<.001)$, such that for one standard unit increase in purpose commitment there was a .055 increase in hope-agency. Purpose commitment was also associated with life satisfaction $(\beta=.201, p<.001)$, such that every one standard unit increase in purpose commitment was associated with a .201 increase in life satisfaction. Identity commitment was associated with life satisfaction ( $\beta$ $=.071, p=.020$ ), such that for each standard deviation increase in identity commitment there was a .071 increase in life satisfaction.

These results support the hypothesis that purpose commitment mediates the relation between identity commitment and well-being (as measured by hope and life satisfaction) among Hispanic emerging adult women. Indirect effects are presented in Table 4 and mediation effects are depicted in Figures 3, 4, and 5. Partial mediation and full mediation occurred with respect to the variables in Study I. Purpose commitment fully mediated the relation between identity commitment and both hope subscales, and partially mediated the relation between identity commitment and life satisfaction.

Full mediation was supported because the indirect path from identity commitment to hope-agency through purpose commitment was significant $(\beta=.030, p<.001)$, but the direct path from identity commitment to hope-agency was not $(\beta=.012, p=.128)$. Likewise, the indirect path from identity commitment to hope-pathways through purpose commitment was statistically significant $(\beta=.030, p<.001)$, but the direct path from identity commitment to hope-pathways was not $(\beta=.008, p=.420)$, thus supporting full mediation. In the case of life satisfaction, both the indirect effect $(\beta=.142, p<.001)$ and 
the direct effect ( $\beta=.071, p=.020)$ were statistically significant, supporting partial mediation. Thus, Hypotheses 1-B and 1-C were supported by the data, because purpose commitment fully mediated the relationship of ego identity commitment to hope-agency to and hope-pathways, and partially mediated the relationship of ego identity commitment to life satisfaction,

\section{Study II: Marianismo, Ethnic Identity, Acculturation and Identity}

The objective of Study II was to examine the effects of marianismo, ethnic identity, and acculturation on identity commitment among emerging adult Hispanic women. Three hypotheses were posited, namely that marianismo would be negatively associated with ego identity commitment (Hypothesis 2-A), ethnic identity resolution would be positively associated with ego identity commitment (Hypothesis 2-B), and acculturation would be positively associated with ego identity commitment (Hypothesis 2-C).

The descriptive statistics for Study II are presented in Table 5. As noted previously, skewness and kurtosis values of all subscales were within the acceptable range for normality of distribution, with the exception of the non-normal distribution of English Proficiency subscale. This distributional non-normality is thought to reflect the nature of the sample, which was comprised of US college students who could be expected to be proficient in English.

Table 6 presents the correlation values for marianismo, ethnic identity resolution, and the acculturation subscales. Significant positive correlations were found between Spanish proficiency and ethnic identity resolution $(r=.174, p=.001)$, ethnic identity resolution and familiarity with Latino culture $(r=.266, p=.001)$, Spanish proficiency 
and familiarity with Latino culture $(r=.395, p=.001)$, familiarity with Latino culture and familiarity with American culture $(r=.344, p=.001)$, and also between familiarity with American culture and English proficiency $(r=.247, p=.001)$. All other variables exhibited correlations that approached zero, indicating no correlations between variables. Relationships between variables were tested using Structural Equation Modeling and the Mplus statistical software program (Múthen \& Múthen, 1998-2010). Only direct effects were specified. These effects are presented in Table 7 and Figure 7.

\section{Hypothesis Testing}

Hypothesis 2-A. It was hypothesized that levels of marianismo would be negatively associated with identity commitment among emerging adult Hispanic women. This hypothesis was supported, as marianismo was negatively associated with identity commitment $(\beta=-.016, p=.047)$; specifically, for every increase in identity commitment that exceeded one standard deviation over the mean, there was an associated decrease of .016 in level of marianismo. Therefore, Hypothesis 2-A was supported by the data, which demonstrated that marianismo was negatively associated with ego identity commitment among emerging adult Hispanic women.

Hypothesis 2-B. Hypothesis 2-B posited that ethnic identity resolution would be positively related to identity commitment. This hypothesis was not supported by the data, as ethnic identity resolution did not exhibit a significant effect on ego identity commitment $(\beta=.018, p=.256)$. Therefore, Hypothesis $2-\mathrm{B}$, which posited that ethnic identity resolution would be positively associated with ego identity commitment among emerging adult Hispanic women, was not supported. 
Hypothesis 2-C. Hypothesis 2-C posited that acculturation would be positively associated with ego identity commitment. In the current study, acculturation was measured by Spanish language proficiency, English language proficiency, familiarization with Latino culture, and familiarity with American culture. Results indicated a significant positive direct effect between familiarity with American culture and ego identity commitment $(\beta=.286, p=.007)$. The direct effects of Spanish proficiency $(\beta=.135, p=$ $.070)$ and familiarization with Latino culture $(\beta=.128, p=.087)$ on ego identity commitment were marginally significant $(p<.10)$. Findings indicated that for every increase in ego identity commitment that was one standard deviation above the mean, there was a .286 increase in level of familiarity with American culture, a .135 increase in Spanish proficiency, and a .128 increase in familiarization with Latino culture. Therefore, Hypothesis 2-C was largely supported by the data, with the caveat that there were no significant findings with regards to English proficiency and its relationship to ego identity commitment. 


\section{DISCUSSION}

Two studies were undertaken in the current research, both of which focused on ego identity commitment among emerging adult Hispanic women. Study I replicated the work of Burrow and Hill (2011) by examining the meditational effects of purpose on the relation between identity and well-being. Study II extended this research further by examining the relation between marianismo, ethnic identity, acculturation and identity commitment. The results of these studies are discussed separately, followed by a discussion of limitations of the research, implications of the studies, and future research directions.

\section{Study I: Identity Commitment, Purpose Commitment, and Well-Being}

Results from Study I replicated the work of Burrow and Hill (2011), as purpose commitment fully mediated the relationships between identity commitment and hope and partially mediated the relation between identity commitment and life satisfaction. These results address the need for studies that investigate identity development among people from immigrant backgrounds (Schwartz, et al., 2006). These findings also help to address the gap in the literature noted by Ryff (1989), that indicates a paucity of literature regarding the impact of ethnicity on an individual's sense that her or his life has a purpose, and on whether or not that person has been able to harness his or her abilities (Keyes et al., 2002).

Although more research needs to be done on identity, purpose, hope, and life satisfaction among diverse populations, the findings from Study I replicated the initial findings that were found among a multiethnic sample of men and women. Thus the results from Study I indicated that there was conceptual convergence regarding identity, 
purpose, and well-being across the two distinct samples. This is also noteworthy because the original study from Burrow and Hill (2011) took place at a university where the total minority enrollment for undergraduate students was 32\% in 2012 (Dstem, 2012), whereas the current research took place at a Hispanic Serving Institution, where Hispanics comprise $66 \%$ of the student body (HSI; Hispanic Association of Colleges and Universities, 2013). Thus, the current research contributed to the literature by replicating the original study at a majority-minority institution, given that most studies on identity development among ethnic minorities take place at universities whose student populations are predominantly non-Hispanic White (Owles, 2009).

\section{Study II: Marianismo, Ethnic Identity, Acculturation and Identity}

The aim of Study II was to examine marianismo, ethnic identity, and acculturation as they related to identity commitment among emerging adult Hispanic women. Marianismo was found to be negatively associated with identity commitment, which supported the hypothesized relationship. Although the size of the relationship was relatively small, it is notable that there were significant findings regarding marianismo in the current research. The tenets of marianismo run counter to the values associated with college enrollment, which espouses personal achievement and assertiveness (Alvarez, 1999; Vasquez, 1997). Thus the current sample of Hispanic college women would be less likely to endorse the traditional gender role beliefs associated with marianismo. Therefore, the results of the current research demonstrate the salience of traditional cultural themes that present themselves above and beyond ethnic identity.

The hypothesized relationship between ethnic identity resolution and ego identity commitment was not supported by the findings of the current study. By placing this 
finding within a greater context, it is possible to consider a plausible explanation as to why there was no significant effect of ethnic identity resolution on personal identity commitment. The participants in the current study had self-identified as Hispanic and were attending a Hispanic Serving Institution. It is possible that the salience or personal meaning of an individual's ethnic identity may take on a different form when that person engages with an environment that is heavily populated with individuals who are from similar ethnic backgrounds. In other words, the participants of the current study are ethnic minorities nationally, but not locally, and certainly not at the university where they are matriculating. Owles (2009) interviewed Cuban American women who were students at the same institution where the current research took place. She found that the participants in her study did not view themselves as ethnic minorities because of the high Hispanic population in Miami. Only when they engaged with other students or exited the greater Miami community did they become aware of their ethnic minority status at the macro level (Owles, 2009). By taking this into consideration, it becomes plausible that ethnic identity may not play as strong a role in ego identity formation when an individual is part of the majority population within her immediate environment.

With regard to acculturation, the results of Study II revealed that familiarity with American culture, Spanish proficiency, and especially familiarity with American culture were associated with ego identity commitment. The current findings also underscore the suggestion by Schwartz et al. (2013) that exploration of an individual's personal identity and cultural identity may go hand in hand for members of different cultural and ethnic groups. This can be contrasted with the lack of findings regarding ethnic identity, and suggests that acculturation may be more salient than ethnic identity given the 
characteristics of the current sample. The results of the current study underscore the importance of including measures of both ethnic identity and acculturation when examining results from a multicultural sample. They are also consistent with the Schwartz et al. (2013) finding that individuals who were higher in both American and Hispanic acculturation measures were higher in identity commitment, which supports the hypothesis that bicultural competence is adaptive.

\section{Limitations of the Research}

The current research sheds light on the role of identity and purpose among emerging adults and highlights culturally relevant factors that may affect identity commitment. However, the current research is not without limitations. First, the sample was comprised solely of emerging adult Hispanic women, which limits the generalizability of the findings. Moreover, the current research used a sample of convenience because the participants were college students who received course credit for their participation, which further limits the generalizability of the findings. In addition, the study relied entirely on self-report data. The self-report nature of the data may have contributed to common method bias (Podsakoff, MacKenzie, Lee, \& Podsakoff, 2003), which must be taken into account when considering the implications of the findings.

Furthermore, the current investigation employed a cross-sectional design that did not allow for the assessment of causality among the study variables. Although findings suggest that identity and purpose were associated with well-being as measured by hope and life satisfaction, it is not possible to conclude definitively that identity or purpose cause well-being. The current research also relied entirely on person-level variables, 
which did not take into account ecological or systemic effects. Moreover, the present research was a replication and extension of a study which was developed through a specific framework and methodology applied by the original researchers. Considering that $35 \%$ of the sample was born outside of the United States, and approximately $50 \%$ of the sample would be considered second-generation Americans, the methodology of the current research is limited because immigration status was not a variable of interest. Future studies should include examine the relation between identity and immigration status.

\section{Implications and Future Directions}

It is notable that the original findings were fully replicated in the current study because it was conceivable that the constructs of identity and purpose and the outcome variables of hope and life satisfaction would be experienced differently for this culturally distinct population of students. Students at the university where the current research took place are mostly commuter students, and many live with their parents while attending college. Thus, the participants in the current study are more likely to have experiences similar to those described by Young (1992), who found that Mexican American women in college were likely to work while going to school and tending to family matters. Therefore, it is possible that culture may play a role for participants in the current research because she may adapt her or his personal identity according to various ecological realms (Cooper, 1999). In addition, the Hispanic women in the current sample may feel encouraged to assimilate to the collegiate culture (Gloria \& Rodriguez, 2000) while rectifying any discrepancies between their cultural values and those of the university community (Gloria \& Robinson Kurpius, 1996). 
The results of the current study have implications for the field of positive youth development, which maintains a focus on positive and desirable outcomes for youth (Bowers et al., 2010). More importantly, results from the current research studies represent an application of positive youth development concepts to a sample of Hispanic women enrolled in college, who are generally underrepresented in the literature. The fact that the results of Burrow and Hill's (2011) initial work were replicated in the current research indicates that identity, purpose, hope, and life satisfaction may not be subject to influence from variables that are demographic in nature (i.e., gender and ethnicity). In addition, the findings of the current research underscore the importance of purpose as a mediator of the effects of identity on hope and life satisfaction among emerging adult Hispanic women who are enrolled in college.

It is significant that these findings were replicated in a sample of Hispanic college students. Hispanics comprise only $16.5 \%$ of all students enrolled in US colleges and universities (Pew Hispanic Center, 2012), even though they are the largest ethnic minority group on American college campuses (Cauchon \& Overberg, 2012). Twentyfive percent of Hispanics in the United States do not obtain a high school diploma or its equivalency (Gerald \& Hussar, 2010, p. 9), and only $8.5 \%$ of students who obtained a bachelor's degree in 2010 were Hispanic (Pew Research Hispanic Center, 2012). Because of the discrepancy in degree attainment among Hispanics, it is important for research to examine the experience of Hispanics enrolled in college and to view college enrollment as a positive developmental outcome.

If enrollment in college is viewed as a positive developmental outcome, then the results of Study 1 underscore the need to develop interventions for adolescents that 
cultivate the character strengths of identity and purpose as a means to foster positive development and the pursuit of positive developmental trajectories, which may include post secondary education. These findings can inform the research on positive youth development because they illustrate the importance of identity and purpose as concepts that are associated with well-being among emerging adults from various ethnic backgrounds attending distinct institutions of higher learning.

The results of Study II have implications particularly regarding the experience of emerging adult Hispanic women enrolled in college. It appears that even though a Hispanic woman may be enrolled in college in the United States, she may still feel the influence of traditional Hispanic gender role beliefs that are associated with detrimental outcomes such as intimate partner violence (Moreno, 2007). Therefore, the current findings support interventions that serve to empower young women in such a way that is culturally sensitive yet self-affirming.

In addition, the current study yields findings that suggest that marianismo and acculturation are associated with ego identity development, which in turn is associated with well-being. Thus the current study suggests that gender and culture must inform the student health programs at the collegiate level. Moreover, as the current study suggests that the identity of Hispanic women in college is informed by issues of gender and culture, positive youth development interventions that wish to promote positive trajectories for women of various ethnicities must consider the influence of culture and gender in positive youth development. Future studies should also examine the relation between identity and familismo, which may indicate the influence of parental values (Levine \& Padilla, 1980). 
In general, it is worth noting that the Eriksonian model of identity development is not informed by issues of gender, ethnicity, or culture. Thus the measure of identity used in the current study may not accurately reflect the construct of ego identity as it is experienced among a sample of Hispanic women. Most immigrants living in the US are from collectivist societies (Steiner, 2009; Van de Vijver, Fons, \& Phalet, 2004) whose values may contrast with American culture (Schwartz et al., 2013). The significant findings of acculturation effects on ego identity commitment in the current sample provide a glimpse into the future with regards to higher education in the United States. The college campus serves as a microcosm of the increasingly diverse American cultural landscape, and the current findings highlight the multifaceted nature of identity among emerging adult Hispanic women. Results from the current study demonstrate the need to employ measures that are culturally informed and reinforce the need to develop culturally informed measures. Future studies will benefit from applying a systemic or ecological framework to the relations between identity, purpose, and well-being among emerging adult Hispanic women. Research is also needed to expand the present findings to other ethnic minorities and to develop culturally appropriate constructs and measures in order to assess positive development in a multicultural context. 


\section{REFERENCES}

Adams, G. R., \& Marshall, S. K. (1996). A developmental social psychology of identity: Understanding the person-in-context. Journal of Adolescence, 19, 429-442.

Alvarez, M. (1999). Diversity among Latinas: Implications for college mental health. In Y. M. Jenkins (Ed.), Diversity in College Settings: Directives for Helping Professionals (pp. 99-115). New York: Routledge.

Aries, E., \& Moorehead, K. (1989). The importance of ethnicity in the development of identity of black adolescents. Psychological Reports, 65, 75-82.

Arnau, R. C., Martinez, P., de Guzmán, I. N., Herth, K., \& Konishi, C. Y. (2010). A Spanish-language version of the Herth Hope Scale: Development and psychometric evaluation in a Peruvian sample. Educational and Psychological Measurement, 70, 808-824.

Arnett, J. J. (2000). Emerging adulthood: A theory of development from the late teens through the twenties. American Psychologist, 55, 469.

Arredondo, P. (2002). Mujeres latinas--Santas y marquesas. Cultural Diversity and Ethnic Minority Psychology, 8, 308-319.

Balistreri, E., Busch-Rossnagel, N., \& Geisinger, K. F. (1995). Development and preliminary validation of the Ego Identity Process Questionnaire. Journal of Adolescence, 18, 179-192.

Bandura, A. (1982). Self-efficacy mechanism in human agency. American Psychologist, $37,122-147$.

Bennion, L. D., \& Adams, G. R. (1986). A revision of the extended version of the objective measure of ego identity status: An identity instrument for use with late adolescents. Journal of Adolescent Research, 1, 183-197.

Benson, P. L. (2006). All kids are our kids: What communities must do to raise caring and responsible children and adolescents. San Francisco, CA: Jossey-Bass.

Berman, A. M., Schwartz, S. J., Kurtines, W. M., \& Berman, S. L. (2001). The process of exploration in identity formation: The role of style and competence. Journal of Adolescence, 24, 513-528.

Berry, J. W. (1980). Acculturation as varieties of adaptation. In A. Padilla (Ed.), Acculturation: Theory, models and some new findings (pp. 9-25). Boulder, CO: Westview. 
Berry, J. W., Trimble, J. E., \& Olmedo, E. L. (1986). Field methods in cross-cultural research. In W. J. Lonner, \& J. W. Berry (Eds.), Cross-cultural research and methodology series. (pp. 291-324). Thousand Oaks, CA: Sage Publications.

Berry, J. W. (1998). Acculturation and health: Theory and research. In S. S. Kazarian \& D. R. Evans (Eds.), Cultural clinical psychology: Theory, research, and practice. (pp. 39-57). New York: Oxford University Press.

Berry, J. W., Phinney, J. S., Sam, D. L., \& Vedder, P. (2006). Immigrant youth: Acculturation, identity, and adaptation. Applied Psychology: An International Review, 55, 303-332.

Berzonsky, M. D. (1992). Identity style and coping strategies. Journal of Personality, 60, 771-788.

Bhatia, S., \& Ram, A. (2001). Rethinking 'acculturation' in relation to diasporic cultures and postcolonial identities. Human Development, 44, 1-18.

Bollen, K. A., \& Long, J. S. (Eds.). (1993). Testing structural equation models. London, UK: Sage Publications.

Bosma, H. A., \& Kunnen, E. S. (2001). Determinants and mechanisms in ego identity development: A review and synthesis. Developmental Review, 21, 39-66.

Bowers, E. P., Li, Y., Kiely, M. K., Brittian, A., Lerner, J. V., \& Lerner, R. M. (2010). The Five Cs model of positive youth development: A longitudinal analysis of confirmatory factor structure and measurement invariance. Journal of Youth and Adolescence, 39, 720-735.

Bradley, R. H., \& Corwyn, R. F. (2004). Life satisfaction among European American, African American, Chinese American, Mexican American, and Dominican American adolescents. International Journal of Behavioral Development, 28, $385-400$.

Branch, C. W., Tayal, P., \& Triplett, C. (2000). The relationship of ethnic identity and ego identity status among adolescents and young adults. International Journal of Intercultural Relations, 24, 777-790.

Branscombe, N. R., Schmitt, M. T., \& Harvey, R. D. (1999). Perceiving pervasive discrimination among African Americans: Implications for group identification and well-being. Journal of Personality and Social Psychology, 77, 135-149.

Bronk, K. C., Hill, P. L., Lapsley, D. K., Talib, T. L., \& Finch, H. (2009). Purpose, hope, and life satisfaction in three age groups. The Journal of Positive Psychology, 4, 500-510. 
Bryant, F. B., \& Cvengros, J. A. (2004). Distinguishing hope and optimism: Two sides of a coin, or two separate coins? Journal of Social and Clinical Psychology, 23, 273302.

Bundick, M., Andrews, M., Jones, A., Mariano, J., Bronk, K., \& Damon, W. (2006). Revised youth purpose survey. Unpublished Instrument. Stanford, CA: Stanford Center on Adolescence.

Burrow, A. L., O'Dell, A., \& Hill, P. L. (2010). Profiles of a developmental asset: Youth purpose as a context for hope and well-being. Journal of Youth and Adolescence, 39, 1265-1273.

Burrow, A. L., \& Hill, P. L. (2011). Purpose as a form of identity capital for positive youth adjustment. Developmental Psychology, 47, 1196-1206.

Burrow, A. L., Sumner, R., \& Ong, A. D. (2013). Perceived change in life satisfaction and daily negative affect: The moderating role of purpose in life. Journal of Happiness Studies, 15, 1-14.

Caldera, Y. M., Robitschek, C., Frame, M., \& Pannell, M. (2003). Intrapersonal, familial, and cultural factors in the commitment to a career choice of Mexican American and non-Hispanic white college women. Journal of Counseling Psychology, 50, 309-323.

Cano, S. (2003). Acculturation, marianismo, and satisfaction with marianismo: An analysis of depression in Mexican American college women. (Unpublished doctoral dissertation). University of Houston, Texas.

Castillo, L. G., \& Cano, M. A. (2008). Mexican American psychology: Theory and clinical application. Reno, NV: Bent Tree Press.

Castillo, L. G., Perez, F. V., Castillo, R., \& Ghosheh, M. R. (2010). Construction and initial validation of the marianismo beliefs scale. Counseling Psychology Quarterly, 23, 163-175.

Cauchon, D., \& Overberg, P. (2012). Census: Rich-poor gap widens. Miami Times, pp. 9D-10D.

Chida, Y., \& Steptoe, A. (2008). Positive psychological well-being and mortality: A quantitative review of prospective observational studies. Psychosomatic Medicine, 70, 741-756. 
Cohen, J. (2003). A power primer. In A. E. Kazdin (Ed.), Methodological Issues and Strategies in Clinical Research (427-436). Washington DC: American Psychological Association.

Cohn, M. A., Fredrickson, B. L., Brown, S. L., Mikels, J. A., \& Conway, A. M. (2009). Happiness unpacked: Positive emotions increase life satisfaction by building resilience. Emotion, 9, 361-368.

Cooper, C. R. (1999). Multiple selves, multiple worlds: Cultural perspectives on individuality and connectedness in adolescent development. Cultural processes in child development, 29, 25-57.

Côté, J. E. (1996). Sociological perspectives on identity formation: The culture-identity link and identity capital. Journal of Adolescence, 19, 417-428.

Côte, J., \& Bynner, J. (2008). Changes in the transition to adulthood in the UK and Canada: The role of structure and agency in emerging adulthood. Journal of Youth Studies, 11, 251-268.

Côté, J. E., \& Levine, C. G. (2002). Identity formation, agency, and culture: A social psychological synthesis. Mahwah, NJ: Lawrence Erlbaum Associates Publishers.

Côte, J. E., \& Schwartz, S. J. (2002). Comparing psychological and sociological approaches to identity: Identity status, identity capital, and the individualization process. Journal of Adolescence, 25, 571-586.

Cramer, P. (1995). Identity, narcissism, and defense mechanisms in late adolescence. Journal of Research in Personality, 29, 341-361.

Crumbaugh, J. C., \& Maholick, L. T. (1964). An experimental study in existentialism: The psychometric approach to Frankl's concept of noogenic neurosis. Journal of Clinical Psychology, 20, 200-207.

Cummins, R. A., \& Nistico, H. (2002). Maintaining life satisfaction: The role of positive cognitive bias. Journal of Happiness Studies, 3, 37-69.

Damon, W. (2008). The path to purpose: Helping our children find their calling in life. New York: Free Press.

Damon, W., Menon, J., \& Bronk, K. C. (2003). The development of purpose during adolescence. Applied Developmental Science, 7, 119-128.

Debats, D. L. (1998). Measurement of personal meaning: The psychometric properties of the life regard index. Mahwah, NJ: Lawrence Erlbaum Associates Publishers. 
Diaz, M. S. (2004). Erikson's theory of development and its relevance and application to hispanic females' identity formation (Erik Erikson). (Unpublished doctoral dissertation). Chicago School of Professional Psychology, Illinois.

Diener, E. (2000). Subjective well-being: The science of happiness and a proposal for a national index. American Psychologist, 55(1), 34-43.

Diener, E., \& Diener, M. (1995). Cross-cultural correlates of life satisfaction and selfesteem. Journal of Personality and Social Psychology, 68(4), 653-663.

Diener, E., Emmons, R. A., Larsen, R. J., \& Griffin, S. (1985). The satisfaction with life scale. Journal of Personality Assessment, 49, 71-75.

Diener, E., Russell, J. A., Barrett, L. F., Watson, D., Wiese, D., Vaidya, J. \& Truax, K. M. (1999). The structure of emotion. Journal of Personality and Social Psychology, 76, 803-866.

Dillon, F. R., Félix-Ortiz, M., Rice, C., De La Rosa, M., Rojas, P., \& Duan, R. (2009). Validating the Multidimensional Measure of Cultural Identity Scales for Latinos among latina mothers and daughters. Cultural Diversity and Ethnic Minority Psychology, 15, 191-201.

Dstem (2012, April 24). Minorities at Loyola face challenges. Retrieved from http://blogs.luc.edu/hubbub/writing-for-the-web/being-a-minority-at-loyola/

Edwards, L. M., Ong, A. D., \& Lopez, S. J. (2007). Hope measurement in Mexican American youth. Hispanic Journal of Behavioral Sciences, 29, 225-241.

Erikson, E. H. (1950). Childhood and society. New York, NY: W. W. Norton \& Co.

Erikson, E. H. (1964). Insight and Responsibility: Lectures on the Ethical Implications of Psychoanalytic Insight. New York, NY: W. W. Norton \& Co.

Erikson, E. H. (1968). Identity: Youth and crisis. Oxford, England: Norton \& Company.

Fadjukoff, P., Pulkkinen, L., \& Kokko, K. (2005). Identity processes in adulthood: Diverging domains. Identity: An International Journal of Theory and Research, 5(1), 1-20.

Félix-Ortiz, M., Newcomb, M. D., \& Myers, H. (1994). A multidimensional measure of cultural identity for Latino and Latina adolescents. Hispanic Journal of Behavioral Sciences, 16, 99-115.

Frankl, V. E. (1963). Man's search for meaning: An introduction to Logotherapy. Oxford, England: Washington Square Press. 
French, S., \& Joseph, S. (1999). Religiosity and its association with happiness, purpose in life, and self-actualization. Mental Health, Religion \& Culture, 2(2), 117-120.

Frucht, S. L. (1995). Family interaction, ethnic identity, and ego identity: A study of mexican-american adolescents. (Unpublished doctoral dissertation). California School of Professional Psychology, Berkeley/Alameda).

Gamst, G., Dana, R. H., Der-Karabetian, A., Aragón, M., Arellano, L. M., \& Kramer, T. (2002). Effects of Latino acculturation and ethnic identity on mental health outcomes. Hispanic Journal of Behavioral Sciences, 24, 479-504.

Gerald, D. E., \& Hussar, W. J. (2000). Projections to 2010. National Center for Education Statistics, 2(3), 7.

Gibb, J. (1990). The hope scale revisited: Further validation of a measure of individual differences in the hope motive. (Unpublished master's thesis). University of Illinois at Urbana-Champaign, Illinois.

Gil, R. M., \& Vazquez, C. I. (1996). The Maria paradox. New York: Perigree Books.

Ginorio, A. B., Gutiérrez, L., Cauce, A. M., \& Acosta, M. (1995). In H. Landrine (Ed.), Bringing cultural diversity to feminist psychology: Theory, research, and practice, (pp. 241-263). Washington, DC: American Psychological Association.

Gloria, A. M., Castellanos, J., \& Orozco, V. (2005). Perceived educational barriers, cultural fit, coping responses, and psychological well-being of Latina undergraduates. Hispanic Journal of Behavioral Sciences, 27, 161-183.

Gloria, A. M., \& Pope-Davis, D. B. (1997). Cultural ambience: The importance of a culturally aware learning environment in the training and education of counselors. In D. B. Pope-Davis \& H. L. K. Coleman (Eds.), Multicultural counseling competencies: Assessment, education and training, and supervision, (242-259). Thousand Oaks, CA: Sage Publications, Inc.

Gloria, A. M., \& Robinson Kurpius, S. E. R. (1996). The validation of the cultural congruity scale and the university environment scale with Chicano/a students. Hispanic Journal of Behavioral Sciences, 18, 533-549.

Gloria, A. M., \& Rodriguez, E. R. (2000). Counseling Latino university students: Psychosociocultural issues for consideration. Journal of Counseling \& Development, 78, 145-154. 
Gross, J. J., \& John, O. P. (2003). Individual differences in two emotion regulation processes: Implications for affect, relationships, and well-being. Journal of Personality and Social Psychology, 85, 348-362.

Grotevant, H. D. (1987). Toward a process model of identity formation. Journal of Adolescent Research, 2, 203-222.

Hall, G. S. (1904). Adolescence: Its psychology and its relations to physiology, anthropology, sociology, sex, crime, religion and education. New York: D. Appleton and Company.

Hamilton, S. F., Hamilton, M. A., \& Pittman, K. (2004). Principles for youth development. Thousand Oaks, CA, US: Sage Publications, Inc.

Hartwig, F., \& Dearing, B. E. (1979). Exploratory data analysis. Newbury Park, CA: Sage Publications.

Hayes, S. C., Strosahl, K. D., \& Wilson, K. G. (1999). Acceptance and commitment therapy: An experiential approach to behavior change. New York, NY: Guilford Press.

Hill, P. L., \& Burrow, A. L. (2012). Viewing purpose through an Eriksonian lens. Identity: An International Journal of Theory and Research, 12, 74-91.

Hill, P. L., Burrow, A. L., Brandenberger, J. W., Lapsley, D. K., \& Quaranto, J. C. (2010). Collegiate purpose orientations and well-being in early and middle adulthood. Journal of Applied Developmental Psychology, 31, 173-179.

Hinds, P. S. (1984). Inducing a definition of "hope" through the use of grounded theory methodology. Journal of Advanced Nursing, 9, 357-362.

Hispanic Association of Colleges and Universities. List of Hispanic Serving Institutions. Retrieved May 29, 2013, Retrieved from http://www.hacu.net/hacu/HSIs.asp

Irving, L., Crenshaw, W., Snyder, C. R., Francis, P., \& Gentry, G. (1990). Hope and its correlates in a psychiatric inpatient setting. 62nd Annual Meeting of the Midwestern Psychological Association, Chicago, Illinois.

Jensen, L. A. (2003). Coming of age in a multicultural world: Globalization and adolescent cultural identity formation. Applied Developmental Science, 7, 189196.

Jezzini, A. T. (2013). Acculturation, marianismo gender role, and ambivalent sexism in predicting depression in Latinas. (Unpublished doctoral dissertation). University of Denver, Colorado. 
Kağitçibaşi, Ç. (2007). Family, self, and human development across cultures: Theories and applications (2nd ed.) Lawrence Erlbaum Associates Publishers, Mahwah, NJ

Kashdan, T. B., \& McKnight, P. E. (2009). Origins of purpose in life: Refining our understanding of a life well lived. Psihologijske teme, 18, 303-313.

Keyes, C., L.M., Shmotkin, D., \& Ryff, C., D. (2002). Optimizing wellbeing: The empirical encounter of two traditions. Journal of Personality and Social Psychology, 82, 1007-1022.

Kiang, L., \& Fuligni, A. J. (2010). Meaning in life as a mediator of ethnic identity and adjustment among adolescents from Latin, Asian, and European American backgrounds. Journal of Youth and Adolescence, 39, 1253-1264.

Kish, G. B., \& Moody, D. R. (1989). Psychopathology and life purpose. The International Forum for Logotherapy, 12, 40-45.

Kroger, J. (2003). Identity development during adolescence. Malden, MA: Blackwell Publishing.

Kroger, J. (2007). Identity development: Adolescence through adulthood. Thousand Oaks, CA: Sage Publications.

Kulis, S., Marsiglia, F. F., Lingard, E. C., Nieri, T., \& Nagoshi, J. (2008). Gender identity and substance use among students in two high schools in Monterrey, Mexico. Drug and Alcohol Dependence, 95, 258-268.

Kuperminc, G. P., Wilkins, N. J., Roche, C., \& Alvarez-Jimenez, A. (2009). Risk, resilience, and positive development among Latino youth. Thousand Oaks, CA: Sage Publications, Inc.

Lara, L. G. (2009). A mixed method study of factors associated with the academic achievement of Latina/o college students from predominantly Mexican American backgrounds: A strengths-based approach. (Unpublished doctoral dissertation). University of Northern Colorado, Colorado.

Lavrin, A. (2004). Latin American women's history: The national project. Women's History in Global Perspective, 1, 180-221.

Lerner, R. M., Dowling, E. M., \& Anderson, P. M. (2003). Positive youth development: Thriving as the basis of personhood and civil society. Applied Developmental Science, 7, 172-180. 
Lerner, R. M., Lerner, J. V., Almerigi, J. B., Theokas, C., Phelps, E., Gestsdottir, S., \& Ma, L. (2005). Positive youth development, participation in community youth development programs, and community contributions of fifth-grade adolescents findings from the first wave of the 4-H study of positive youth development. The Journal of Early Adolescence, 25, 17-71.

Lerner, R. M., von Eye, A., Lerner, J. V., Lewin-Bizan, S., \& Bowers, E. P. (2010). Special issue introduction: The meaning and measurement of thriving: A view of the issues. Journal of Youth and Adolescence, 39, 707-719.

Leung, J., \& Leung, K. (1992). Life satisfaction, self-concept, and relationship with parents in adolescence. Journal of Youth and Adolescence, 21, 653-665.

LeVine, E. S., \& Padilla, A. M. (1980). Crossing cultures in therapy: Pluralistic counseling for the Hispanic. Monterey, CA: Brooks/Cole.

Liebkind, K. (2006). Ethnic identity and acculturation. In D. L. Sam \& J. W. Berry (Eds.), The Cambridge Handbook of Acculturation Psychology. New York, NY: Cambridge University Press.

Liebkind, K., \& Jasinskaja-Lahti, I. (2000). Acculturation and psychological well-being among immigrant adolescents in Finland: A comparative study of adolescents from different cultural backgrounds. Journal of Adolescent Research, 15, 446469.

Lujan, V. B. (2008). Education biographies from the science pipeline: An analysis of Latino/a student perspectives on ethnic and gender identity in higher education. (Unpublished doctoral dissertation). The University of Texas at Austin, Texas.

Luyckx, K., Goossens, L., Soenens, B., \& Beyers, W. (2006). Unpacking commitment and exploration: Preliminary validation of an integrative model of late adolescent identity formation. Journal of Adolescence, 29, 361-378.

Luyckx, K., Goossens, L., Soenens, B., Beyers, W., \& Vansteenkiste, M. (2005). Identity statuses based on 4 rather than 2 identity dimensions: Extending and refining Marcia's paradigm. Journal of Youth and Adolescence, 34, 605-618.

Magaletta, P. R., \& Oliver, J. M. (1999). The hope construct, will, and ways: Their relations with self-efficacy, optimism, and general well-being. Journal of Clinical Psychology, 55, 539-551.

Marcia, J. E. (1966). Development and validation of ego-identity status. Journal of Personality and Social Psychology, 3, 551-558. 
Marcia, J. E. (1980). Identity in adolescence. Handbook of Adolescent Psychology, 9, 159-187.

Mariano, J. M. (2007). Relationship of purpose to character strengths in emerging adulthood. (Unpublished doctoral dissertation). Stanford University, California.

McKnight, P. E., \& Kashdan, T. B. (2009). Purpose in life as a system that creates and sustains health and well-being: An integrative, testable theory. Review of General Psychology, 13, 242-251.

Meeus, W., Iedema, J., Helsen, M., \& Vollebergh, W. (1999). Patterns of adolescent identity development: Review of literature and longitudinal analysis. Developmental Review, 19, 419-461.

Miller, J. F., \& Powers, M. J. (1988). Development of an instrument to measure hope. Nursing Research, 37, 6-10.

Miville, M. L., \& Helms, J. E. (1996). Exploring relationships of cultural, gender, and personal identity among Latinos and Latinas. Paper presented at the Annual Meeting of the American Psychological Association, Toronto, Canada.

Miville, M. L., Koonce, D., Darlington, P., \& Whitlock, B. (2000). Exploring the relationships between racial/cultural identity and ego identity among African Americans and Mexican Americans. Journal of Multicultural Counseling and Development, 28, 208-224.

Moreno, C. L. (2007). The relationship between culture, gender, structural factors, abuse, trauma, and HIV/AIDS for Latinas. Qualitative Health Research, 17, 340-352.

Morris, M. W., \& Peng, K. (1994). Culture and cause: American and Chinese attributions for social and physical events. Journal of Personality and Social Psychology, 67, 949-971.

Muthén, L.K. and Muthén, B.O. (1998-2010). Mplus user's guide. Sixth Edition. Los Angeles, CA: Muthén \& Muthén.

Niemann, Y. F. (2001). Stereotypes about Chicanas and Chicanos: Implications for counseling. The Counseling Psychologist, 29, 55-90.

Nieves-Squires, S. (1991). Hispanic women: Making their presence on campus less tenuous. Washington, DC: Association of American Colleges.

Ojeda, L., Flores, L. Y., \& Navarro, R. L. (2011). Social cognitive predictors of Mexican American college students' academic and life satisfaction. Journal of Counseling Psychology, 58, 61-71. 
Ojeda, L., Navarro, R. L., Rosales Meza, R., \& Arbona, C. (2012). Too Latino and not Latino enough: The role of ethnicity-related stressors on Latino college students' life satisfaction. Journal of Hispanic Higher Education, 11, 14-28.

Owles, V. (2009). The experiences of Cuban American women attending a Hispanic serving institution and the influences on identity development. (Unpublished doctoral dissertation). Florida International University, Florida.

Pacico, J. C., Zanon, C., Bastianello, M. R., \& Hutz, C. S. (2011). Adaptation and validation of the hope index for Brazilian adolescents. Psicologia: Reflexão e Crítica, 24, 666-670.

Padilla, A. M., \& Perez, W. (2003). Acculturation, social identity, and social cognition: A new perspective. Hispanic Journal of Behavioral Sciences, 25, 35-55.

Park, N., Peterson, C., \& Seligman, M. E. (2004). Strengths of character and well-being. Journal of Social and Clinical Psychology, 23, 603-619.

Peterson, C., \& Seligman, M. E. P. (2004). Character strengths and virtues: A handbook and classification. Washington, DC: Oxford University Press.

Pew Research Hispanic Center. (2012). Hispanic student enrollments reach new highs in 2011. Retrieved from http://www.pewhispanic.org/2012/08/20/hispanic-studentenrollments-reach-new-highs-in-2011/

Phinney, J. S. (1989). Stages of ethnic identity development in minority group adolescents. The Journal of Early Adolescence, 9(1-2), 34-49.

Phinney, J. S. (1990). Ethnic identity in adolescents and adults: Review of research. Psychological Bulletin, 108, 499-514.

Phinney, J. S. (1992). The Multigroup Ethnic Identity Measure: A new scale for use with diverse groups. Journal of Adolescent Research, 7, 156-176.

Phinney, J. S. (1996). When we talk about American ethnic groups, what do we mean? American Psychologist, 51, 918-927.

Phinney, J. S., \& Alipuria, L. L. (1990). Ethnic identity in college students from four ethnic groups. Journal of Adolescence, 13, 171-183.

Phinney, J. S., Horenczyk, G., Liebkind, K., \& Vedder, P. (2001). Ethnic identity, immigration, and well-being: An interactional perspective. Journal of Social Issues, 57, 493-510. 
Phinney, J. S., Kim-Jo, T., Osorio, S., \& Vilhjalmsdottir, P. (2005). Autonomy and relatedness in adolescent-parent disagreements ethnic and developmental factors. Journal of Adolescent Research, 20, 8-39.

Phinney, J. S., \& Ong, A. D. (2007). Conceptualization and measurement of ethnic identity: Current status and future directions. Journal of Counseling Psychology, $54,271-281$.

Piña-Watson, B., Castillo, L. G., Ojeda, L., \& Rodriguez, K. M. (2013). Parent conflict as a mediator between marianismo beliefs and depressive symptoms for Mexican American college women. Journal of American College Health, 61, 491-496.

Podsakoff, P. M., MacKenzie, S. B., Lee, J., \& Podsakoff, N. P. (2003). Common method biases in behavioral research: A critical review of the literature and recommended remedies. Journal of Applied Psychology, 88, 879-903.

Portes, A., \& Rumbaut, R.G. (2006). Immigrant America: A portrait (3rd ed.). Berkley, CA, University of California Press.

Portes, A., \& Stepick, A. (1994). City on the edge: The transformation of Miami ( $2^{\text {nd }}$ ed.). Berkeley, CA: University of California Press.

Rivera-Marano, M. R. (2000). The creation of the Latina Values Scale: An analysis of marianismo's effect of Latina women attending college. (Unpublished doctoral dissertation). Rutgers The State University of New Jersey, New Jersey.

Roberts, R. E., Phinney, J. S., Masse, L. C., Chen, Y. R., Roberts, C. R., \& Romero, A. (1999). The structure of ethnic identity of young adolescents from diverse ethnocultural groups. The Journal of Early Adolescence, 19, 301-322.

Rocha-Sánchez, T. E., \& Díaz-Loving, R. (2005). Cultural de género: La brecha ideológica entre hombres y mujeres. Anales De Psicología, 21, 42-49.

Rodriguez, A. L., Guido-DiBrito, F., Torres, V., \& Talbot, D. (2000). Latina college students: Issues and challenges for the 21st century. Naspa Journal, 37, 511-527.

Rodriguez, N., Myers, H., F., Morris, J.,K., \& Cardoza, D. (2000). Latino college student adjustment: Does an increased presence offset minority-status and acculturative stresses? Journal of Applied Social Psychology, 30, 1523-1550.

Rogler, L. H., Cortes, D. E., \& Malgady, R. G. (1991). Acculturation and mental health status among Hispanics: Convergence and new directions for research. American Psychologist, 46, 585-597. 
Roth, J. L., \& Brooks-Gunn, J. (2003). What exactly is a youth development program? Answers from research and practice. Applied Developmental Science, 7, 94-111.

Rudmin, F. W. (2003). Critical history of the acculturation psychology of assimilation, separation, integration, and marginalization. Review of General Psychology, 7, 337.

Ryff, C. D. (1989). Happiness is everything, or is it? Explorations on the meaning of psychological well-being. Journal of Personality and Social Psychology, 57, 1069-1081.

Ryff, C. D., Keyes, C. L. M., \& Hughes, D. L. (2003). Status inequalities, perceived discrimination, and eudaimonic well-being: Do the challenges of minority life hone purpose and growth? Journal of Health and Social Behavior, 44, 275-291.

Saldaña, D. H. (1994). Acculturative stress: Minority status and distress. Hispanic Journal of Behavioral Sciences, 16, 116-128.

Schrank, B., Stanghellini, G., \& Slade, M. (2008). Hope in psychiatry: A review of the literature. Acta Psychiatrica Scandinavica, 118, 421-433.

Schwartz, S. J. S. (2002). Convergent validity in objective measures of identity status: Implications for identity status theory. Adolescence, 37, 609-625.

Schwartz, S. J. (2007). Addressing the challenges and opportunities for today's youth: Toward an integrative model and its implications for research and intervention. The Journal of Primary Prevention, 28, 117-144.

Schwartz, S. J., Côté, J. E., \& Arnett, J. J. (2005). Identity and agency in emerging adulthood: Two developmental routes in the individualization process. Youth \& Society, 37, 201-229.

Schwartz, S. J., Kim, S. Y., Whitbourne, S. K., Zamboanga, B. L., Weisskirch, R. S., Forthun, L. F., \& Luyckx, K. (2013). Converging identities: Dimensions of acculturation and personal identity status among immigrant college students. Cultural Diversity and Ethnic Minority Psychology, 19, 155-165.

Schwartz, S. J., Mason, C. A., Pantin, H., \& Szapocznik, J. (2009). Longitudinal relationships between family functioning and identity development in hispanic adolescents: Continuity and change. The Journal of Early Adolescence, 29, 177211.

Schwartz, S. J., Montgomery, M. J., \& Briones, E. (2006). The role of identity in acculturation among immigrant people: Theoretical propositions, empirical questions, and applied recommendations. Human Development, 49, 1-30. 
Schwartz, S. J., Zamboanga, B. L., Weisskirch, R. S., \& Rodriguez, L. (2009). The relationships of personal and ethnic identity exploration to indices of adaptive and maladaptive psychosocial functioning. International Journal of Behavioral Development, 33, 131-144.

Scheier, M. F., \& Carver, C. S. (1985). Optimism, coping, and health: Assessment and implications of generalized outcome expectancies. Health Psychology, 4, 219247.

Schumacker, R. E., \& Lomax, R. G. (2010). A beginner's guide to structural equation modeling (3rd ed.) New York, NY: Routledge/Taylor \& Francis Group,.

Seligman, M. E. (2002). Authentic happiness: Using the new positive psychology to realize your potential for lasting fulfillment. New York, NY: Simon and Schuster.

Seligman, M. E., \& Csikszentmihalyi, M. (2000). Positive psychology: An introduction. Washington, DC: American Psychological Association.

Serafini, T. E., \& Adams, G. R. (2002). Functions of identity: Scale construction and validation. Identity, 2, 361-389.

Shek, D. T. (1993). The Chinese purpose-in-life test and psychological well-being in Chinese college students. International Forum for Logotherapy, 16, 35-42.

Smith, M. B. (1983). Hope and despair: Keys to the socio-psychodynamics of youth. American Journal of Orthopsychiatry, 53, 388-399.

Sneed, J. R., Schwartz, S. J., \& Cross, W. E., Jr. (2006). A multicultural critique of identity status theory and research: A call for integration. Identity: An International Journal of Theory and Research, 6, 61-84.

Snyder, C. R. (1994). The psychology of hope: You can get there from here. New York, NY: Free Press.

Snyder, C. R., Harris, C., Anderson, J. R., Holleran, S. A., Irving, L. M., Sigmon, S. T., \& Harney, P. (1991). The will and the ways: Development and validation of an individual-differences measure of hope. Journal of Personality and Social Psychology, 60, 570-585.

Snyder, C. R., Hoza, B., Pelham, W. E., Rapoff, M., Ware, L., Danovsky, M., Highberger, L., Ribinstein, H, \& Stahl, K. J. (1997). The development and validation of the children's hope scale. Journal of Pediatric Psychology, 22, 399421. 
Snyder, C. R., Rand, K. L., \& Sigmon, D. R. (2002). Hope theory: A member of the positive psychology family. In C. R. Snyder \& S. J. Lopez (Eds.), Handbook of positive psychology (pp. 257-276). New York, NY: Oxford University Press.

Snyder, C. R., Sympson, S. C., Michael, S. T., \& Cheavens, J. (2001). Optimism and hope constructs: Variants on a positive expectancy theme. Optimism \& pessimism: Implications for theory, research, and practice. (pp. 101-125)

Spencer, M. B., \& Markstrom-Adams, C. (1990). Identity processes among racial and ethnic minority children in America. Child Development, 61, 290-310.

St. Louis, G. R., \& Liem, J. H. (2005). Ego identity, ethnic identity, and the psychosocial well-being of ethnic minority and majority college students. Identity, 5, 227-246.

Staats, S. (1987). Hope: Expected positive affect in an adult sample. The Journal of Genetic Psychology: Research and Theory on Human Development, 148, 357364.

Steger, M., F., Frazier, P., Oishi, S., \& Kaler, M. (2006). The meaning in life questionnaire: Assessing the presence of and search for meaning in life. Journal of Counseling Psychology, 53, 80-93.

Steiner, N. (2009). International migration and citizenship today. New York, NY: Routledge.

Stevens, E. P. (1973). Machismo and marianismo. Society, 10(6), 57-63.

Stepick, A., Grenier, G., Castro, M., \& Dunn, M. (2003). This land is our land: Immigrants and power in Miami. Berkley, CA: University of California Press.

Stoddard, S. A., \& Garcia, C. M. (2011). Hopefulness among Non U.S. Born Latino youth and young adults. Journal of Child and Adolescent Psychiatric Nursing, 24, 216-222.

Suh, E., Diener, E., Oishi, S., \& Triandis, H. C. (1998). The shifting basis of life satisfaction judgments across cultures: Emotions versus norms. Journal of Personality and Social Psychology, 74, 482-493.

Tajfel, H. (1981). Human groups and social categories: Studies in social psychology. New York, NY: Cambridge University Press.

Terry, T., \& Huebner, E. S. (1995). The relationship between self-concept and life satisfaction in children. Social Indicators Research, 35, 39-52. 
Triandis, H. C. (1989). The self and social behavior in differing cultural contexts. Psychological Review, 96, 506-520.

U. S. Census Bureau. (2011). 2010 census shows nation's Hispanic population grew four times faster than total U.S. population. Retrieved July 19, 2012, from http://www.census.gov/newsroom/releases/archives/2010_census/cb11cn146.html

Umaña-Taylor, A. J., \& Updegraff, K. A. (2007). Latino adolescents' mental health: Exploring the interrelations among discrimination, ethnic identity, cultural orientation, self-esteem, and depressive symptoms. Journal of Adolescence, 30, 549-567.

Umaña-Taylor, A. J., Vargas-Chanes, D., Garcia, C. D., \& Gonzales-Backen, M. (2008). A longitudinal examination of Latino adolescents' ethnic identity, coping with discrimination, and self-esteem. The Journal of Early Adolescence, 28, 16-50.

Umaña-Taylor, A. J., Yazedjian, A., \& Bámaca-Gómez, M. (2004). Developing the ethnic identity scale using Eriksonian and social identity perspectives. Identity: An International Journal of Theory and Research, 4, 9-38.

Unger, J. B., Ritt-Olson, A., Wagner, K., Soto, D., \& Baezconde-Garbanati, L. (2007). A comparison of acculturation measures among Hispanic/Latino adolescents. Journal of Youth and Adolescence, 36, 555-565.

Vasquez, M. J. T. (1997). Confronting barriers to the participation of Mexican American women in higher education. In A. Darder, R. D. Torres, \& H. Gutierrez (Eds.), Latinos and Education: A Critical Reader. New York: Routledge.

Van De Vijver, Fons J. R., \& Phalet, K. (2004). Assessment in multicultural groups: The role of acculturation. Applied Psychology, 53, 215-236.

van Hoof, A., \& Raaijmakers, Q. A. W. (2003). The search for the structure of identity formation. Identity: An International Journal of Theory and Research, 3, 271-289.

Veenhoven, R. (2004). Happiness as an aim in public policy. Hoboken, NJ: John Wiley and Sons, Inc.

Young, G. (1992). Chicana college students on the Texas-Mexico border: Tradition and transformation. Hispanic Journal of Behavioral Sciences, 14, 341-352.

Waterman, A. S. (1992). Identity as an aspect of optimal psychological functioning. In G. R. Adams, T. P. Gullotta, \& R. Montemayor (Eds.), Adolescent identity formation, (pp. 50-72). Thousand Oaks, CA: Sage Publications, Inc. 
Wilcox, R. R. (2012). Introduction to robust estimation and hypothesis testing. New York: Academic Press.

Yalom, I. D. (1980). Existential psychotherapy. New York, NY: Basic Books.

Zimmer-Gembeck, M., J. (2006). Intimacy dating goals and relationship satisfaction during adolescence and emerging adulthood: Identity formation, age and sex as moderators. International Journal of Behavioral Development, 30, 167-177. 


\section{TABLES}

Table 1

Descriptive Statistics of Identity, Purpose, Hope, and Life Satisfaction

\begin{tabular}{llll}
\hline Variable Name & Mean $(S D)$ & Skewness & Kurtosis \\
\hline Identity Commitment & $65.067(10.291)$ & -.014 & -.031 \\
Purpose Commitment & $81.21(14.317)$ & -1.167 & 2.056 \\
Hope-Agency & $123.13(1.852)$ & -.466 & 1.096 \\
Hope-Pathways & $12.86(1.759)$ & -.105 & .551 \\
Satisfaction With Life & $25.11(6.227)$ & -.751 & .632 \\
\hline
\end{tabular}


Table 2

Correlations Between Identity, Purpose, Hope, and Life Satisfaction

\begin{tabular}{lccccc}
\hline \multicolumn{1}{c}{ Variable } & 1 & 2 & 3 & 4 & 5 \\
\hline 1. Identity Commitment & - & & & \\
2. Purpose Commitment & $.469^{* *}$ & - & & \\
3. Hope-Agency & $.305^{* *}$ & $.441^{* *}$ & - & \\
4. Hope-Pathways & $.198^{* *}$ & $.311^{* *}$ & $.609^{* *}$ & - \\
5. Life Satisfaction & $.367^{* *}$ & $.519^{* *}$ & $.508^{* *}$ & $.350^{* *}$ & - \\
\hline
\end{tabular}

** Indicates significance at 0.01 level (2-tailed). 
Table 3

Direct Effects of Identity and Purpose on Hope and Life Satisfaction

\begin{tabular}{lllll}
\hline Outcome & Predictor & Path & P- & $95 \%$ CI \\
& & Coefficient & \multicolumn{2}{l}{ Value } \\
\hline Purpose Commitment & Identity Commitment & $.708(.503)^{* *}$ & .001 & .561 to .856 \\
Hope-Pathways & Purpose Commitment & $.043(.351)^{* *}$ & .001 & .030 to .055 \\
& Identity Commitment & $.008(.044)$ & .420 & -.011 to .026 \\
Hope-Agency & Purpose Commitment & $.055(.428)^{* *}$ & .001 & .038 to .071 \\
& Identity Commitment & $.012(.066)$ & .128 & -.003 to .027 \\
Satisfaction With Life & Purpose Commitment & $.201(.469)^{* *}$ & .001 & .149 to .252 \\
& Identity Commitment & $.071(.117)^{*}$ & .020 & .011 to .130
\end{tabular}

Note: Standardized values in parentheses. $* p<.05 ; * * p<.01$ 
Table 4

Purpose as a Mediator of Relation Between Identity and Well-Being

\begin{tabular}{lll}
\hline & \multicolumn{2}{l}{ Purpose as Mediator } \\
\cline { 2 - 3 } Outcome & Indirect $\beta$ & $95 \%$ CI \\
\hline Hope-Agency & $.039 *(.215)$ & .024 to .054 \\
Hope-Pathways & $.030 *(.176)$ & .019 to .041 \\
Satisfaction With Life & $.142 *(.236)$ & .093 to .191 \\
\hline$* p<.01$ &
\end{tabular}


Table 5

Descriptive Statistics of Marianismo, Ethnic Identity, and Acculturation Variables

\begin{tabular}{lclcc}
\hline Variable & Mean & $\begin{array}{l}\text { Standard } \\
\text { Deviation }\end{array}$ & Skewness & Kurtosis \\
\hline Marianismo & 52.98 & 12.83 & .636 & 1.226 \\
Ethnic Identity Resolution & 12.23 & 3.14 & -.665 & .002 \\
Spanish Proficiency & 9.38 & 2.22 & -.379 & -.688 \\
English Proficiency & 11.54 & 1.17 & -3.37 & 14.38 \\
Familiarity With Latino Culture & 10.19 & 2.91 & -.078 & -.567 \\
Familiarity With American Culture & 13.57 & 2.17 & -1.08 & 1.48 \\
\hline
\end{tabular}


Table 6

Intercorrelations of Marianismo, Ethnic Identity, and Acculturation Variables

\begin{tabular}{lcccccc}
\hline \multicolumn{1}{c}{ Variable } & 1 & 2 & 3 & 4 & 5 & 6 \\
\hline 1. Marianismo & - & & & & \\
2. Ethnic Identity Resolution & -.038 & - & & & \\
3. Spanish Proficiency & .014 & $.174^{* *}$ & - & & \\
4. Familiarity With Latino Culture & .012 & $.266^{* *}$ & $.395^{* *}$ & - & \\
5. English Proficiency & -.042 & .042 & -.022 & -.074 & - \\
6. Familiarity With American Culture & -.050 & .083 & -.006 & $.344^{*}$ & $.247^{* *}$ & - \\
\hline
\end{tabular}

** Indicates significance at 0.01 level (2-tailed). 
Table 7

Effects of Marianismo, Ethnic Identity, and Acculturation on Identity

\begin{tabular}{|c|c|c|c|c|}
\hline Outcome & Predictor & Path Coefficient & $\begin{array}{l}\text { P- } \\
\text { Value }\end{array}$ & $95 \% \mathrm{CI}$ \\
\hline Identity & Marianismo & $-.016(-.110)^{* *}$ & .047 & -.031 to .000 \\
\hline \multirow[t]{5}{*}{ Commitment } & $\begin{array}{l}\text { Ethnic Identity } \\
\text { Resolution }\end{array}$ & $.018(.043)$ & .256 & -.013 to .049 \\
\hline & Spanish Proficiency & $.135(.111)^{*}$ & .070 & -.011 to .281 \\
\hline & English Proficiency & $.056(.044)$ & .482 & -.100 to .212 \\
\hline & $\begin{array}{l}\text { Familiarity With } \\
\text { Latino Culture }\end{array}$ & $.128(.101)^{*}$ & .087 & -.019 to .276 \\
\hline & $\begin{array}{l}\text { Familiarity With } \\
\text { American Culture }\end{array}$ & $.286(.208)^{* * *}$ & .007 & .079 to .492 \\
\hline
\end{tabular}




\section{FIGURES}

Figure 1

Hypothesized Effects of Identity, Purpose, Hope, and Life Satisfaction

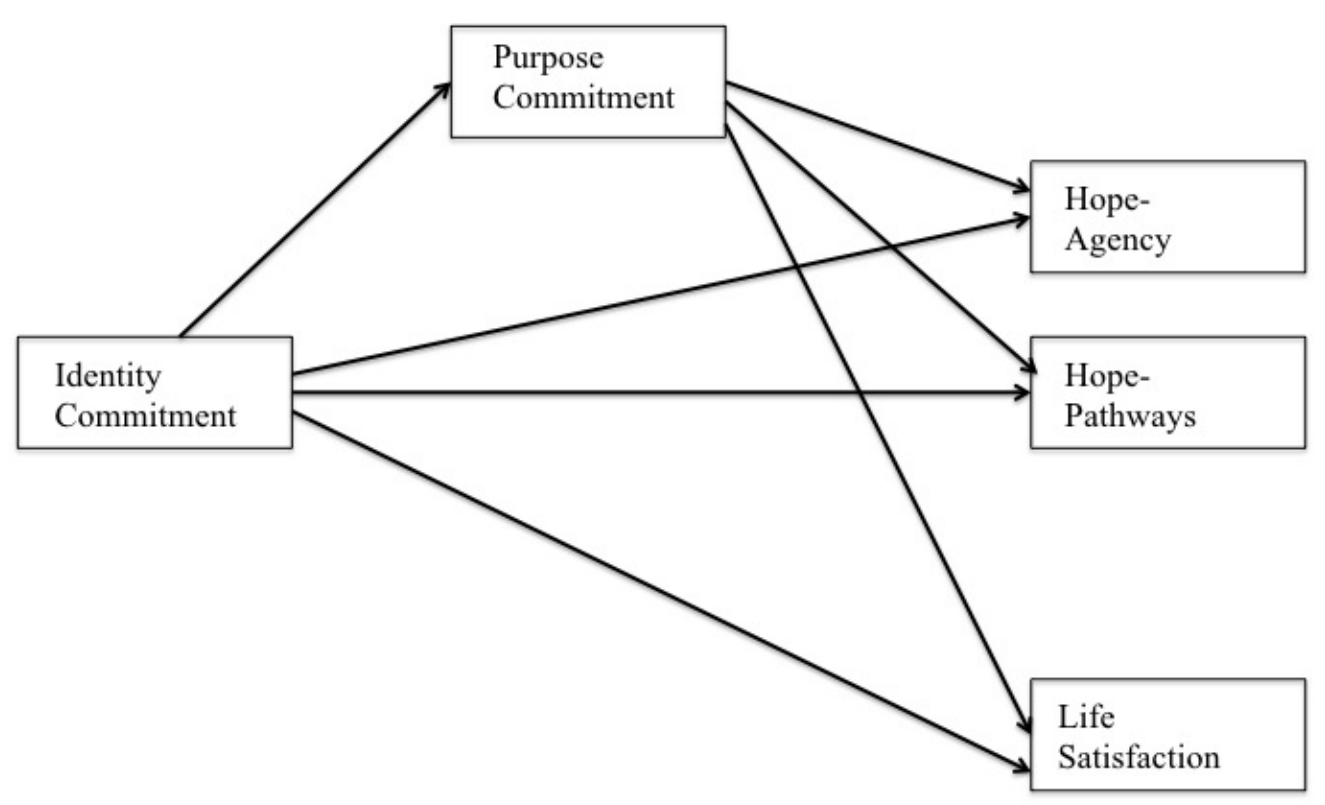


Figure 2

Influence of Identity and Purpose on Hope and Life Satisfaction

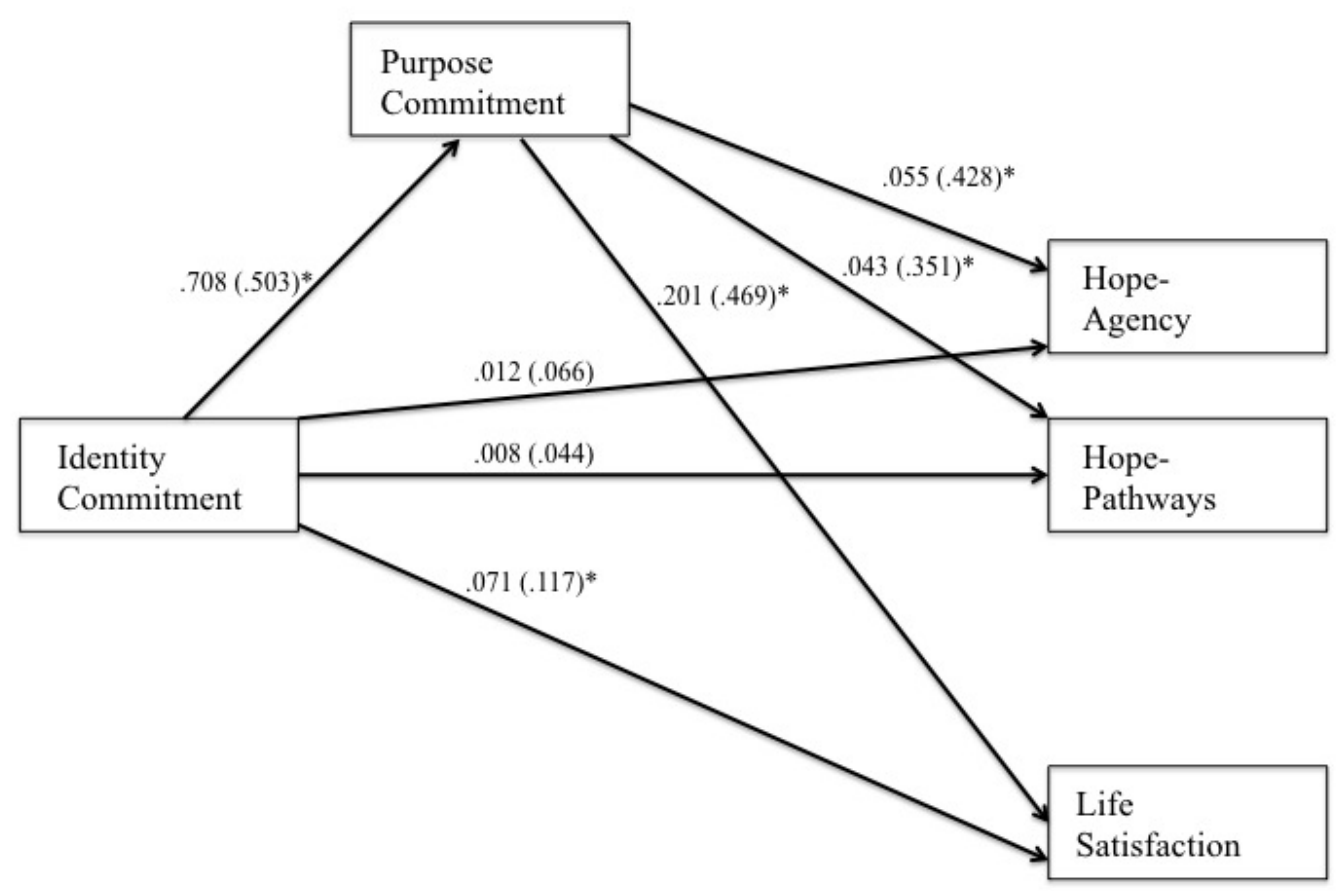

Note: Standardized values in parentheses. ${ }^{*} p<.05$ 
Figure 3

Purpose Mediates the Relation Between Identity and Hope-Agency

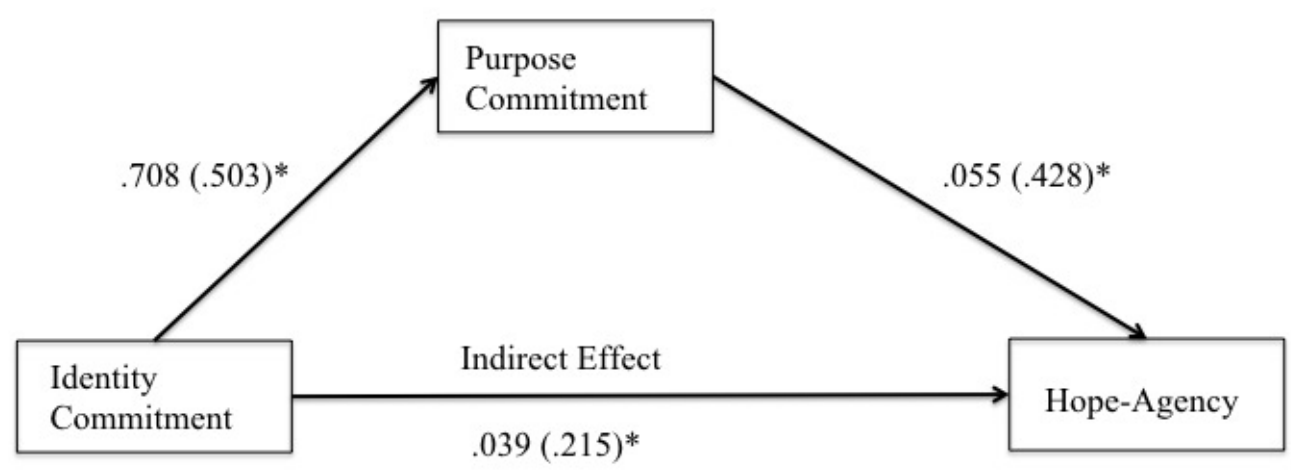

\begin{tabular}{|l|c|c|}
\hline $\begin{array}{l}\text { Identity } \\
\text { Commitment }\end{array}$ & Direct Effect & Hope-Agency \\
\cline { 2 - 3 } & $.012(.066)$ & Hor \\
\hline
\end{tabular}

Note: Standardized values I parentheses. $* p<.05$ 
Figure 4

Purpose Mediates the Relation Between Identity and Hope-Pathways

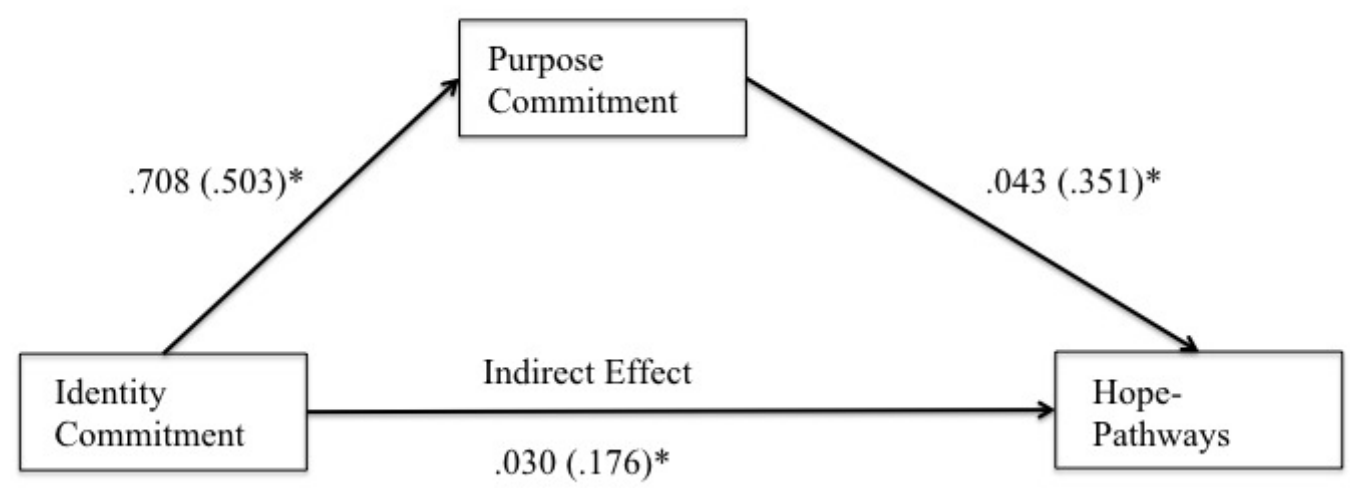

\begin{tabular}{|l|c|l|}
\hline $\begin{array}{l}\text { Identity } \\
\text { Commitment }\end{array}$ & Direct Effect & $\begin{array}{l}\text { Hope- } \\
\text { Pathways }\end{array}$ \\
\cline { 2 - 3 } & $.008(.044)$ &
\end{tabular}

Note: Standardized values in parentheses. ${ }^{*} p<.05$ 
Figure 5

Purpose Mediates the Relation Between Identity and Life Satisfaction

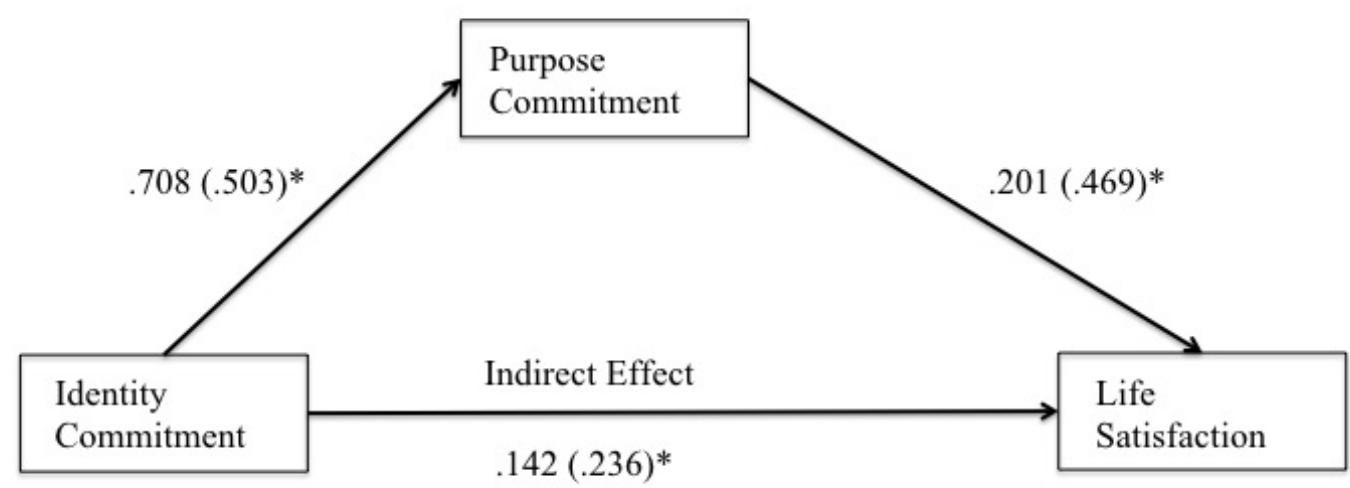

\begin{tabular}{|c|c|c|}
\hline \multirow{2}{*}{$\begin{array}{l}\text { Identity } \\
\text { Commitment }\end{array}$} & Direct Effect & Life \\
\hline & & Satisfaction \\
\hline
\end{tabular}

Note: Standardized values in parentheses. ${ }^{*} p<.05$ 
Figure 6

Hypothesized Effects of Marianismo, Ethnic Identity, and Acculturation on Identity

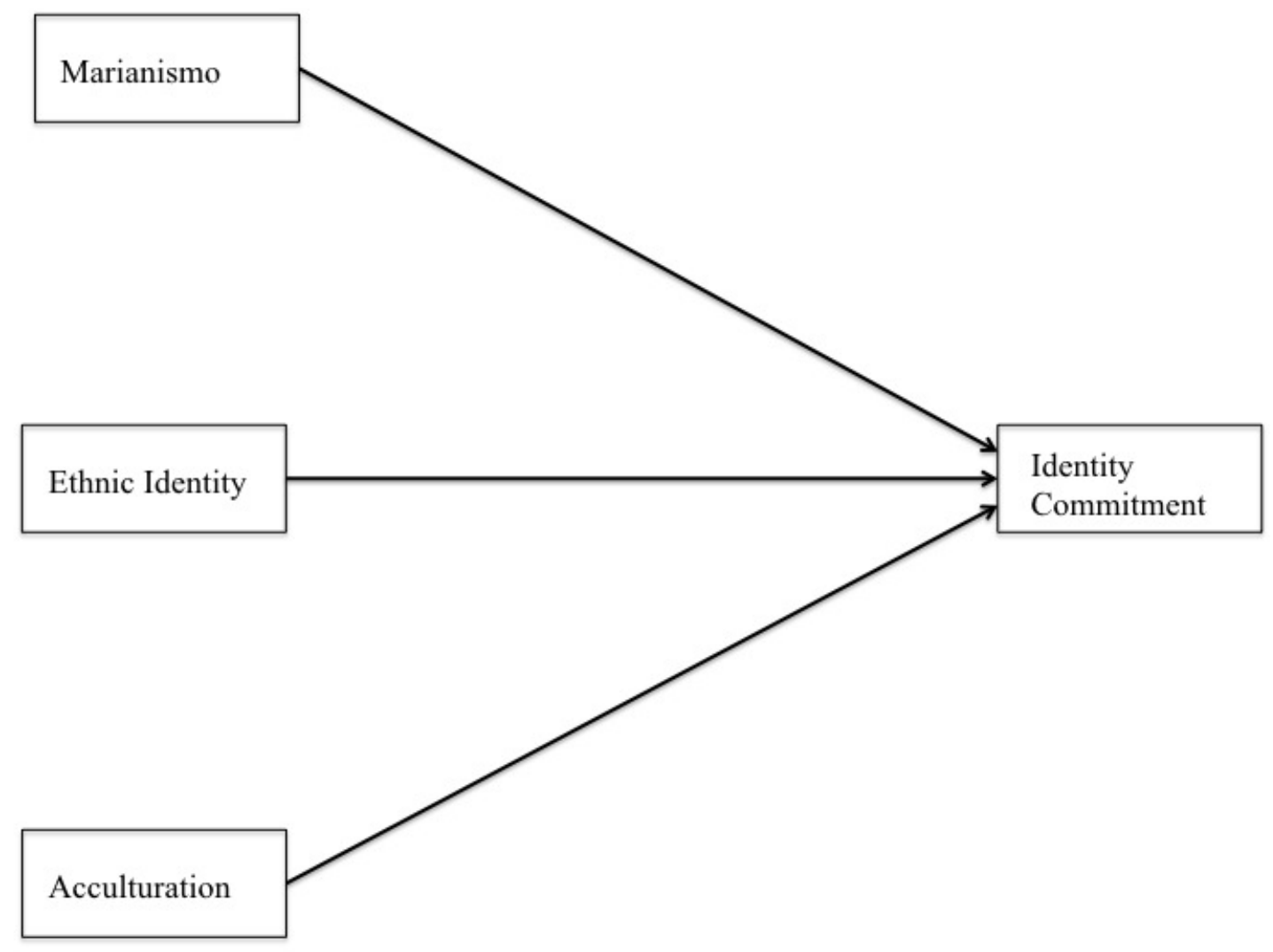


Figure 7

Direct Effects of Marianismo, Ethnic Identity, and Acculturation on Identity

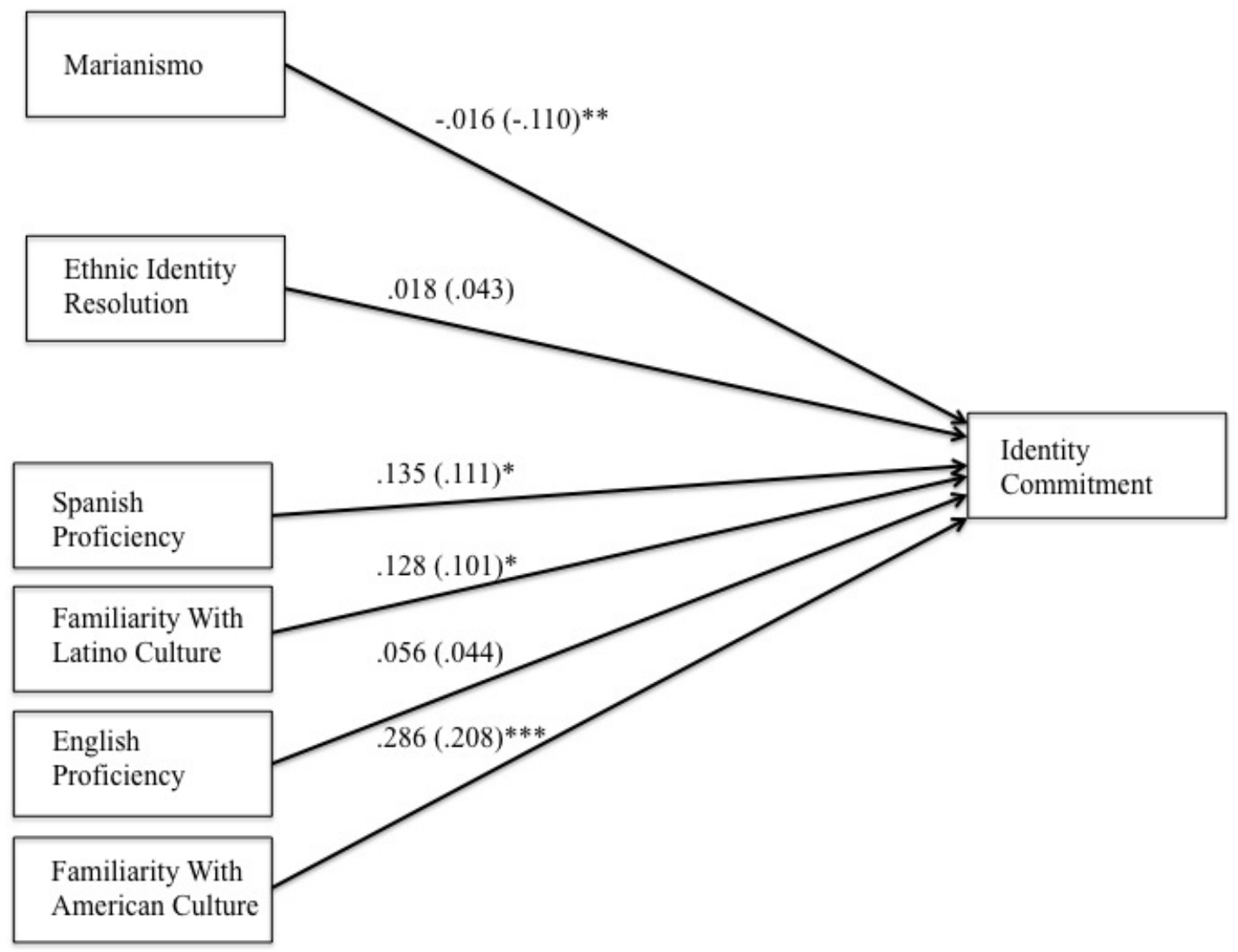

Note: Standardized values in parentheses. ${ }^{*} p<.10 ;{ }^{* *} p<.05 ; * * * p<.01$ 
VITA

\section{VANESSA LYNN MADRAZO}

August 2005

B. A., Psychology

University of Miami

Miami, Florida

August 2007

M. S. Ed., Education

University of Miami

Miami, Florida

August 2011

M. S., Psychology

Florida International University

Miami, Florida

\section{PUBLICATIONS AND PRESENTATIONS}

Ritchie, R. A., Meca, A., Madrazo, V. L., Schwartz, S. J., Hardy, S. A., et al. (2013). Identity Dimensions and Related Processes in Emerging Adulthood: Helpful or Harmful? Journal of Clinical Psychology, 69, 415-432.

Madrazo, V., Meca, A., Maximin, B., \& Stephens, D. (November, 2013). Spirituality and Emerging Adults: The Roles of Gender and Ethnic Identity on Self-Esteem and Perceived Discrimination. Presented at the $8^{\text {th }}$ Biannual Meeting of the Society for the Study of Human Development, Ft. Lauderdale, FL.

Madrazo, V., Meca, A., \& and Stephens, D. P. (June, 2013). The relationship between forgiveness of parents and parenting style among Hispanic emerging adults. Presented at the Biannual Meeting of the International Positive Psychology Association, Los Angeles, CA.

Madrazo, V., Meca, A., Schwartz, S. J., \& Stephens, D. P. (May, 2013). A multiethnic study on the effects of family variables on emotion regulation. Presented at the Annual Meeting of the Association for Psychological Science, Washington, D. C.

Madrazo, V., Meca, A., Ritchie, R., \& Maximin, B. (May, 2013). Identity, purpose, and positive outcomes in Hispanic female college students. Presented at the Biannual Meeting of the Society for Research in Identity Formation, St. Paul, MN.

Maximin, B., Madrazo, V., Meca, A., \& Kurtines, W. (May, 2013). Critical thinking, life goals, and behavioral outcomes - An outcome mediation cascade model. Presented at the Biannual Meeting of the Society for Research in Identity Formation, St. Paul, MN. 
Ritchie, R., Meca, A., Eichas, K., Madrazo, V., Garcia, A., Varela, A., Rinaldi, R., Maximin, B., Kasian, E., Quintana, S., Harari, G., \& Kurtines, W. M. (February, 2011). Mediators of Exploration and Commitment in a Positive Youth Development Project. Presented at the annual meeting of the Society for Research on Identity Formation, Daytona Beach, FL.

Ritchie, R., Meca, A., Madrazo, V., Garcia, A., Eichas, K., Rinaldi, R., \& Kurtines, W. (March, 2010). Investigating Mediators of Identity Development in a School-Based Youth Development Project. Presented at the Annual Meeting of the Society for Research on Identity Formation. Philadelphia, PA.

Meca, A., Eichas, K., Rinaldi, R., Ritchie, R., Garcia, A., Madrazo, V., Ekasian, K, O’Dowd, B., Quintana, S., \& Kurtines, W. (October, 2009). Positive Youth Development: Promoting Control and Responsibility for Life Challenges. Presented at the 6th biennial conference meeting of the Society for the Study of Human Development, Ann Arbor, MI. 